\title{
Geomechanical characterisation of organic-rich calcareous shale using AFM and nanoindentation
}

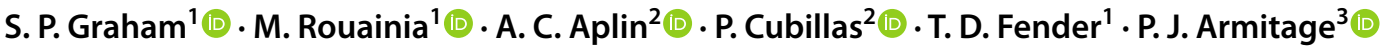

Received: 2 April 2020 / Accepted: 23 September 2020 / Published online: 19 October 2020

(c) The Author(s) 2020

\begin{abstract}
The geomechanical integrity of shale overburden is a highly significant geological risk factor for a range of engineering and energy-related applications including $\mathrm{CO}_{2}$ storage and unconventional hydrocarbon production. This paper aims to provide a comprehensive set of high-quality nano- and micro-mechanical data on shale samples to better constrain the macroscopic mechanical properties that result from the microstructural constituents of shale. We present the first study of the mechanical responses of a calcareous shale over length scales of $10 \mathrm{~nm}$ to $100 \mu \mathrm{m}$, combining approaches involving atomic force microscopy (AFM), and both low-load and high-load nanoindentation. PeakForce quantitative nanomechanical mapping AFM (PF-QNM) and quantitative imaging (QI-AFM) give similar results for Young's modulus up to $25 \mathrm{GPa}$, with both techniques generating values for organic matter of 5-10 GPa. Of the two AFM techniques, only PF-QNM generates robust results at higher moduli, giving similar results to low-load nanoindentation up to $60 \mathrm{GPa}$. Measured moduli for clay, calcite, and quartz-feldspar are $22 \pm 2 \mathrm{GPa}, 42 \pm 8 \mathrm{GPa}$, and $55 \pm 10 \mathrm{GPa}$ respectively. For calcite and quartz-feldspar, these values are significantly lower than measurements made on highly crystalline phases. High-load nanoindentation generates an unimodal mechanical response in the range of 40-50 GPa for both samples studied here, consistent with calcite being the dominant mineral phase. Voigt and Reuss bounds calculated from low-load nanoindentation results for individual phases generate the expected composite value measured by high-load nanoindentation at length scales of 100-600 $\mu \mathrm{m}$. In contrast, moduli measured on more highly crystalline mineral phases using data from literature do not match the composite value. More emphasis should, therefore, be placed on the use of nano- and micro-scale data as the inputs to effective medium models and homogenisation schemes to predict the bulk shale mechanical response.
\end{abstract}

Keywords Calcareous mudstones · Soft rocks · Composite material - Small strain stiffness · Atomic force microscope Nanoindentation $\cdot$ XRD $\cdot$ SEM

\section{Introduction}

Shale is an important material in a range of engineering and energy-related applications including $\mathrm{CO}_{2}$ storage (Armitage et al. 2011), nuclear waste disposal (Guéry et al. 2010), and

S. P. Graham

s.graham4@ncl.ac.uk

$\triangle$ M. Rouainia

M.Rouainia@ncl.ac.uk

1 School of Engineering, Newcastle University, Newcastle upon Tyne NE1 7RU, UK

2 Department of Earth Sciences, Durham University, Durham DH1 3LE, UK

3 Unconventional Gas Technology, BP, Sunbury, Surrey, UK shale gas production. $\mathrm{CO}_{2}$ storage in depleted oil reservoirs requires a re-assessment of the mechanical integrity of the shale seal prior to long term storage since changes in stress state induced by production promote compaction of the overburden (Goulty 2003; Obradors-Prats et al. 2017, 2019). This increases the chance of brittle failure through overconsolidation of the formation rocks (Daigle et al. 2017; Ingram and Urai 1999; Nygård et al. 2004, 2006), or reactivation of existing fractures (Davies et al. 2013). The production of gas and oil from shale requires hydraulic fracturing of the formation, with the elastic properties of the reservoir being important in characterising brittleness (Rybacki et al. 2016) and to the development of a complex fracture network as a function of lithology, diagenesis, and burial history (Rickman et al. 2008). Elastic properties can also be linked to the viscoplastic response thus providing insights to fracture 
closure (Sone and Zoback 2013a, b; Rybacki et al. 2017). Sharp declines in gas production rates following fracturing are typical (Baihly et al. 2010), so a clearer understanding of the controls on the mechanical properties of shale should allow improvements in fracture network optimisation.

Despite its importance, the mechanical properties of shale are poorly constrained. Technical and economic challenges in recovering core limit traditional geomechanical testing (Kumar et al. 2012). The multiscale nature of shale is often overlooked, yet the nano- and micro-scale properties ultimately control both mechanical behaviour and anisotropy (Bobko and Ulm 2008). Since predictive modelling of pore network evolution and fracture growth requires a multiscale approach, characteristic mechanical properties for processes acting at appropriate length scales are needed to calibrate models. The grain size of component minerals in shale range from $<1$ to $100 \mu \mathrm{m}$, making direct mechanical characterisation of individual components difficult. However, developments in instrumental techniques now allow us to access the mechanical properties of materials at smaller length scales, allowing us to more readily access mineralogical and microstructural contributions to mechanical behaviour that were previously impossible to isolate.

Low-load nanoindentation can be used to assess mechanical properties at length scales of $500 \mathrm{~nm}-3000 \mathrm{~nm}$. Previous studies have assessed the mechanical response of the composite clay-organic matrix of shale using statistical deconvolution methods on large datasets (Bobko and Ulm 2008; Ulm and Abousleiman 2006). Because clay and organic material (OM) are often intimately associated in shale, limited measurements of $\mathrm{OM}$ by nanoindentation have been generated (Zeszotarski et al. 2004; Zargari et al. 2013; Abedi et al. 2016). In thermally mature shales, organic matter is highly porous (Loucks et al. 2009, 2012; Zargari et al. 2015), especially at the scale of the nanoindenter tip, so that it is difficult to isolate the mechanical response of pure OM, since the elastic response is heavily influenced by porosity (Goodarzi et al. 2016). Coal has been used as a proxy (Borodich et al. 2015; Vranjes et al. 2018), but is subject to the same problems. The elastic properties of clay are also poorly constrained, with full elastic tensors only being available from molecular dynamics studies (Militzer et al. 2011; Monfared and Ulm 2016).

Atomic force microscopy (AFM) can extract mechanical properties at nanoscale resolution owing to the small diameter $(10-30 \mathrm{~nm})$ of the probe. Coupling with continuum mechanics models (e.g., Derjaguin et al. 1975; Sneddon 1965) makes it possible to measure the mechanical properties of the sample at nanometre resolution (Burnham and Colton 1989). Initially used in biomechanics (Smolyakov et al. 2016) and polymer chemistry (Tomasetti et al. 1998), nanomechanical characterisation modes have only recently been applied to geomechanical problems. Eliyahu et al. (2015), Emmanuel et al. (2016, 2017), Goodarzi et al. (2016), Goodarzi et al. (2017), Li et al. (2018b), Li et al. (2018a) have attempted to extract Young's modulus values from different shales looking at the effects of maturity and temperature on the mechanical properties of OM. These studies all employ the PeakForce ${ }^{\mathrm{TM}}$ quantitative nanomechanical mapping (PF-QNM) technique and suggest that the Young's modulus of organic matter is in the range 1-32 GPa. Recently, Fender et al. (2020) have provided the first application of an alternative form of AFM, the quantitative imaging (QI-AFM), to geological materials for the study of coal macerals. It is therefore required to assess how this technique performs against more established methods to be able to full interpret its results, and to understand how QIAFM may be extended to other geological materials.

Various studies of OM in shale cite other studies to validate their results. However, Jakob et al. (2019) have shown that intra-sample geochemical composition can vary significantly at the nanoscale. Such intra-sample variability therefore precludes inter-sample comparison unless the repeatability of AFM measurements can be demonstrated. The results of Jakob et al. (2019) show that mechanical differences between $\mathrm{OM}$ in shales that are equally mature from the perspective of RockEval may still yield mechanical differences at the nanoscale that are the result of maturity-related heterogeneity. Therefore, demonstrating the repeatability of AFM results is crucial to interpret their mechanics reliably.

Furthermore, Eliyahu et al. (2015) observe that AFM appears to yield different Young's modulus values for mineral phases such as calcite and quartz compared to values reported in the literature (Mavko et al. 2009). It is still unclear if this represents calibration drift in the measurement (Young et al. 2011), or if it represents a true mechanical response due morphological factors, or crystal impurities which can affect its elastic properties (Fournier et al. 2011, 2014). This ambiguity needs to be addressed to fully understand the range of Young's moduli to which AFM can be applied, an in order better understand how we can apply nano- and micro-mechanical data in models.

Mechanical data from AFM are normally validated by comparison to nanoindentation; for example, Young et al. (2011) show good agreement between PF-QNM and nanoindentation results for stiff polymers up to $E \approx 3 \mathrm{GPa}$. However, for organic-rich shales, this method of validation is problematic, since isolating intimately mixed organic matter and clay is difficult. Furthermore, both OM and clay minerals undergo a complex series of chemical reactions during burial, resulting in compositional changes (e.g., Thyberg and Jahren 2011; Jakob et al. 2019) making it difficult to create samples in an equivalent diagenetic state to the shale.

This study aims to address issues surrounding repeatability of AFM measurements combining the use of two 
independent AFM approaches on a single sample. This comparison also serves to assess the performance of QI-AFM relative to PF-QNM as this will show the range of geological materials this method can be applied to. For inorganic, nonclay phases, AFM will be compared to low-load nanoindentation to address the issue of the low Young's moduli for calcite and quartz reported by Eliyahu et al. (2015).

The organic-rich shales used in this study are highly calcareous. Existing micro-mechanical data for well-characterised shales focus on the siliciclastic end-member. Despite this, the Niobrara, Eagle Ford, Green River, Tarfaya, and parts of the Horn River shales are all examples of notable organic-rich, calcareous shales that contribute significantly to hydrocarbon production. The results presented in this study will provide a robust micro-mechanical dataset that is more appropriate for modelling the macro-scale elasticity of calcareous shales.

\section{Sample Characterisation and Preparation}

\subsection{Sample Characterisation}

This study focuses on two shale samples from the dry gas window (Mullen 2010). Sample mineralogy was characterised by X-ray powder diffraction (Table 1). Both samples are carbonate-clay mudstones with clay present as predominantly mixed layer illite-smectite. In addition to bulk rock mineralogy, local compositional mapping was carried out using energy-dispersive X-ray spectroscopy (EDX), with simultaneous acquisition of backscattered electron images (BSE) (Figs. 1, 2). Samples were also analysed for total organic carbon (TOC).

\subsection{Sample Preparation}

AFM requires a flat sample surface. To achieve this, samples were first prepared as thick sections cut perpendicular to the bedding planes. Pucks of $2.5 \mathrm{~mm}$ diameter were then cut from the thick sections and further polished by broad ion beam milling to remove plucking artefacts (Amirmajdi et al. 2009; Loucks et al. 2009) which contribute to significant short wavelength changes in topography. This procedure results in topographic variations on the order of $100 \mathrm{~nm}$ and low surface angles (Fig. 3a). Changes in surface angle are noted where there is a significant contrast in stiffness between adjacent phases (compare Fig. 2 with Fig. 3a), since softer phases are less resistant to milling; however, over $90 \%$ of the surface is inclined at less than $10^{\circ}$ (Fig. 3b), sufficient for AFM analysis.

\section{Analytical Methods}

\subsection{Atomic Force Microscopy}

Two different types of nanomechanical characterisation AFM modes were employed in this study. First, PeakForce quantitative nanomechanical mapping (PF-QNM) was deployed using a Bruker multimode AFM equipped with a Nanoscope V controller. In addition, and for comparison, we use the quantitative imaging (QI) mode developed by JPK, and referred to here as QI-AFM. This uses the nanowizard ${ }^{\mathrm{TM}} \mathrm{III}$ platform. In force spectroscopy mode, a piezoelectric scanner moves the sample/probe vertically. As the tip makes contact with the sample surface, the deflection in the cantilever is measured by the position of the laser on a quadruple photo-diode detector (Fig. 4a). As it approaches, electrostatic forces pull the tip to the surface (adhesive regime). The point at which adhesion is at its maximum value is defined as the tip-sample contact point $\left(z_{\mathrm{c}}\right.$ in Fig. 4b). Beyond this, the tip enters the repulsive contact regime where force increases until the user-defined setpoint (defined in calibration, see Sect. 3.1.2) is reached. This point corresponds to the position of maximum $z$-piezo extension, after which the tip is retracted. The portion of the curve between $z_{c}$ and the setpoint is used for fitting of the contact model from which mechanical properties are calculated (Sect. 3.1.2).

The operation of the AFM outlined above is common to PF-QNM and QI-AFM, with the main difference being the motion z-piezo as a function of time. PF-QNM uses sinusoidal motion in the $z$ direction, whereas QI-AFM uses a sawtooth motion. The sinusoidal motion of the $z$-piezo in PF-QNM results in velocity and acceleration profiles that are also smooth and continuous. The contact model employed by the two systems also differs (see Sect. 3.1.2 for more detail). Another important difference is the oscillation speed of the probe, which varies between 0.25 and $2 \mathrm{kHz}$ for PFQNM and between 0.5 and $100 \mathrm{~Hz}$ for QI-AFM.
Table 1 Sample mineralogy and total organic carbon ( $\mathrm{vol} \%$ )

\begin{tabular}{llllllllllll}
\hline Sample & Qtz & Plg & Cal & Dol & Sid & Ana & Pyr & Mar & Chl & I + I/S + ML & TOC \\
\hline CC8 & 16.6 & 8.4 & 41.0 & 5.4 & 0.1 & 0.1 & 0.7 & 0.2 & 3.2 & 18.9 & 5.4 \\
TS10 & 9.9 & 1.7 & 56.1 & 0.0 & 0.1 & 0.1 & 1.3 & 0.4 & 1.4 & 22.4 & 6.5 \\
\hline
\end{tabular}



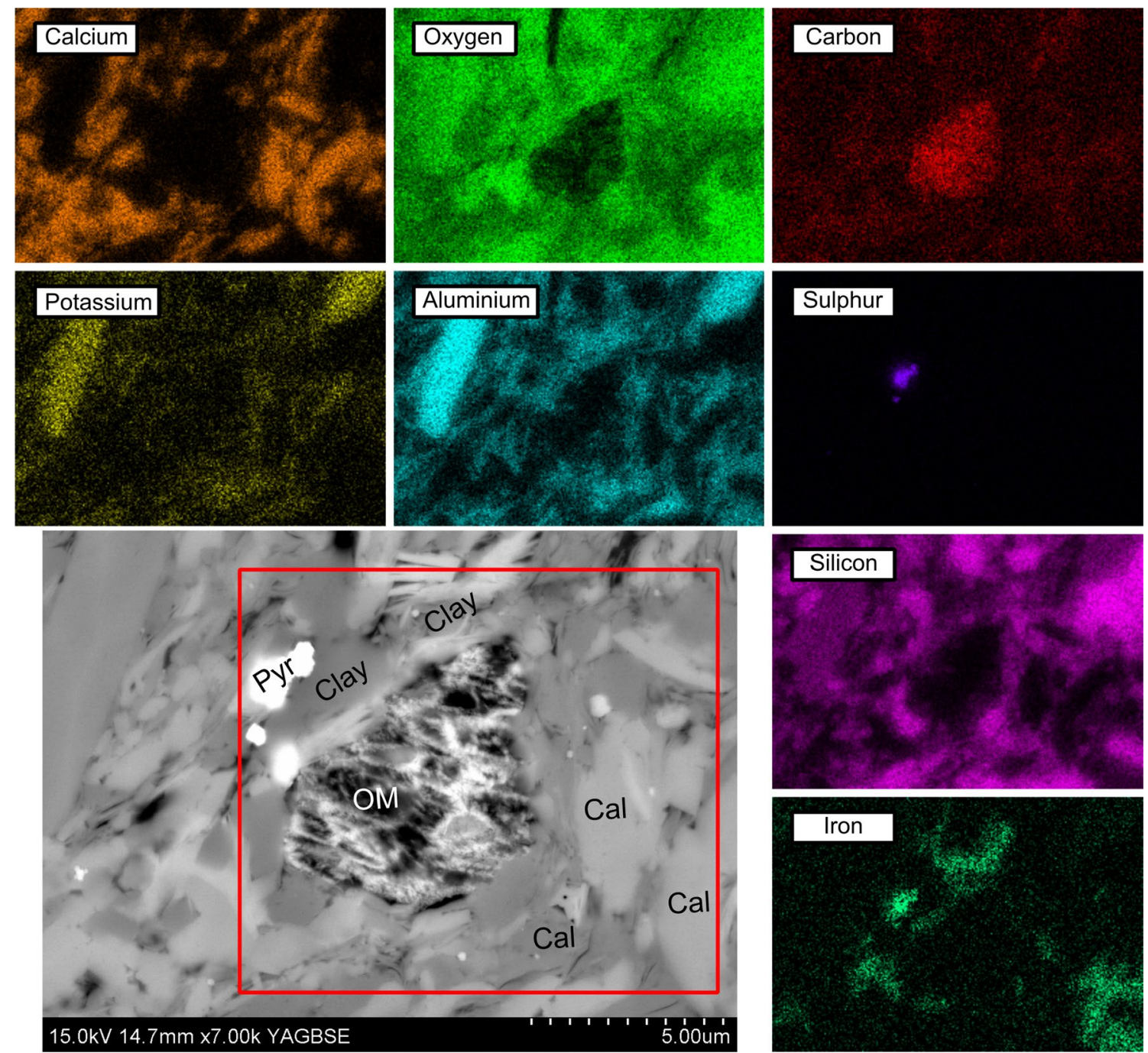

Fig. 1 BSE image of CC8 with associated EDX maps used for mineralogical interpretation. The red box outlines the area targeted for AFM mechanical mapping. OM organic matter, Cal calcite, Clay clay mineral, Pyr pyrite

\subsubsection{AFM Probe Selection}

Successful measurement of the elastic properties of a material by AFM requires an appropriate tip/cantilever assembly. The cantilever needs an adequate spring constant to prevent excessive deformation during contact. The tip must be sufficiently stiff to avoid significant deformation itself. Pittenger et al. $(2014,2011)$ provide the working ranges of commercially available cantilevers and calibration standards. Two tips are suitable (Fig. 5a) for organic matter (OM), but only the DNISP probe is capable of measuring stiffer inorganic phases based on results from existing studies (Eliyahu et al. 2015; Emmanuel et al. 2016, 2017; Goodarzi et al. 2016; $\mathrm{Li}$ et al. 2018a). The DNISP probe has a diamond cornercube tip on a stainless steel cantilever (Fig. 5b), whereas the TAP525 made from silicon nitride. DNISP probes are superior in that they theoretically allow all material components in shale to be characterised without changing tip, but are significantly more expensive.

\subsubsection{Contact Model}

In line with previous studies that use PF-QNM (Eliyahu et al. 2015; Emmanuel et al. 2016; Goodarzi et al. 2016; Emmanuel et al. 2017; Li et al. 2018b), we make use of the Dejaguin-Muller-Toporov (DMT) contact model (Derjaguin et al. 1975) as the basis for our calculation of Young's modulus. This model is an extension of the classical Hertz-Sneddon contact model for the indentation of an elastic half space (Sneddon 1965). The Hertz-Sneddon model is derived for a spherical indenter and is used in this case to approximate the tip of the AFM probes. In this scheme, the so-called reduced Young's modulus is given by: 

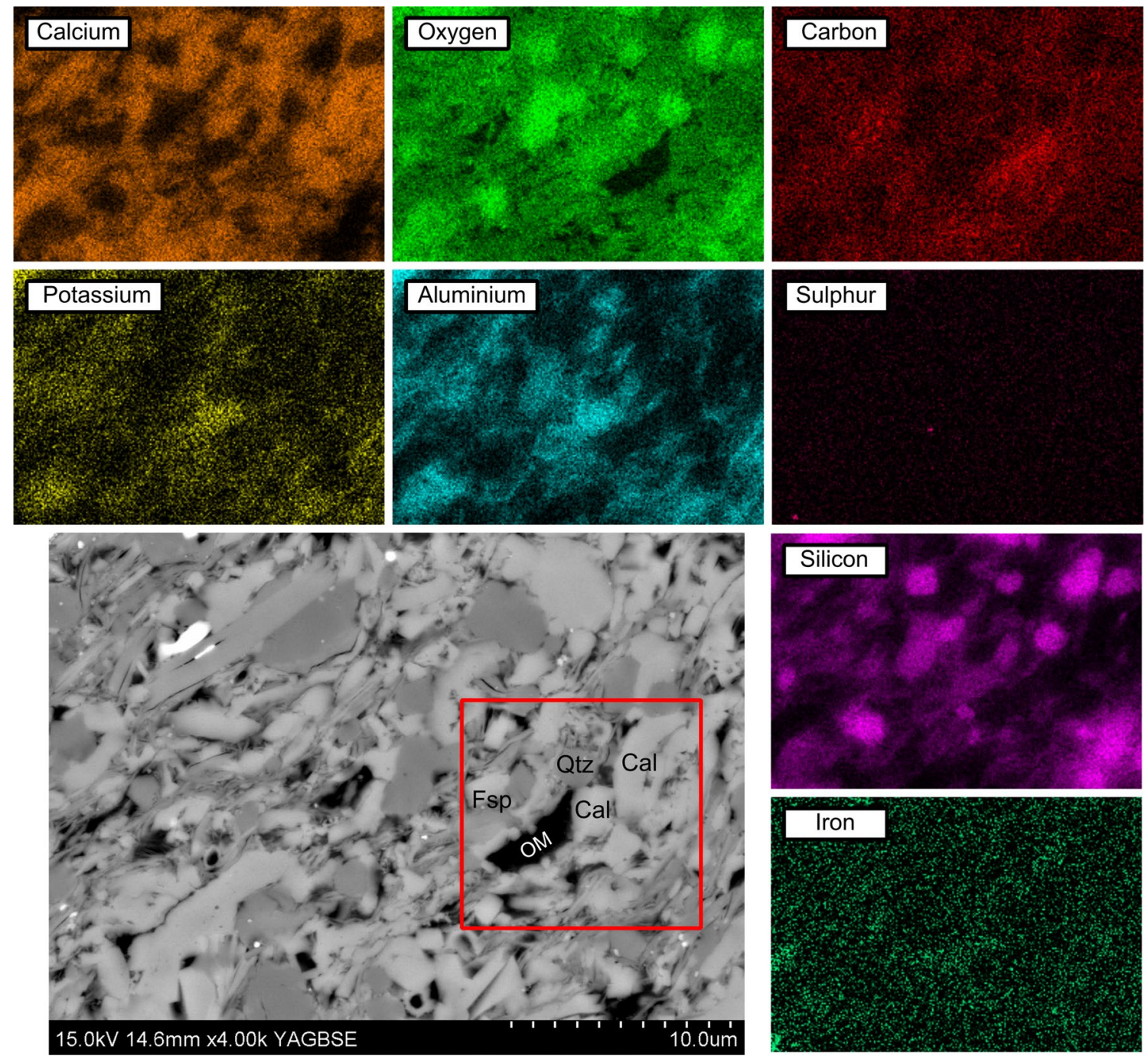

Fig. 2 BSE image of TS10 with associated EDX maps used for mineralogical interpretation. The red box outlines the area targeted for AFM mechanical mapping. OM organic matter, Cal calcite, Qtz quartz, Fsp feldspar
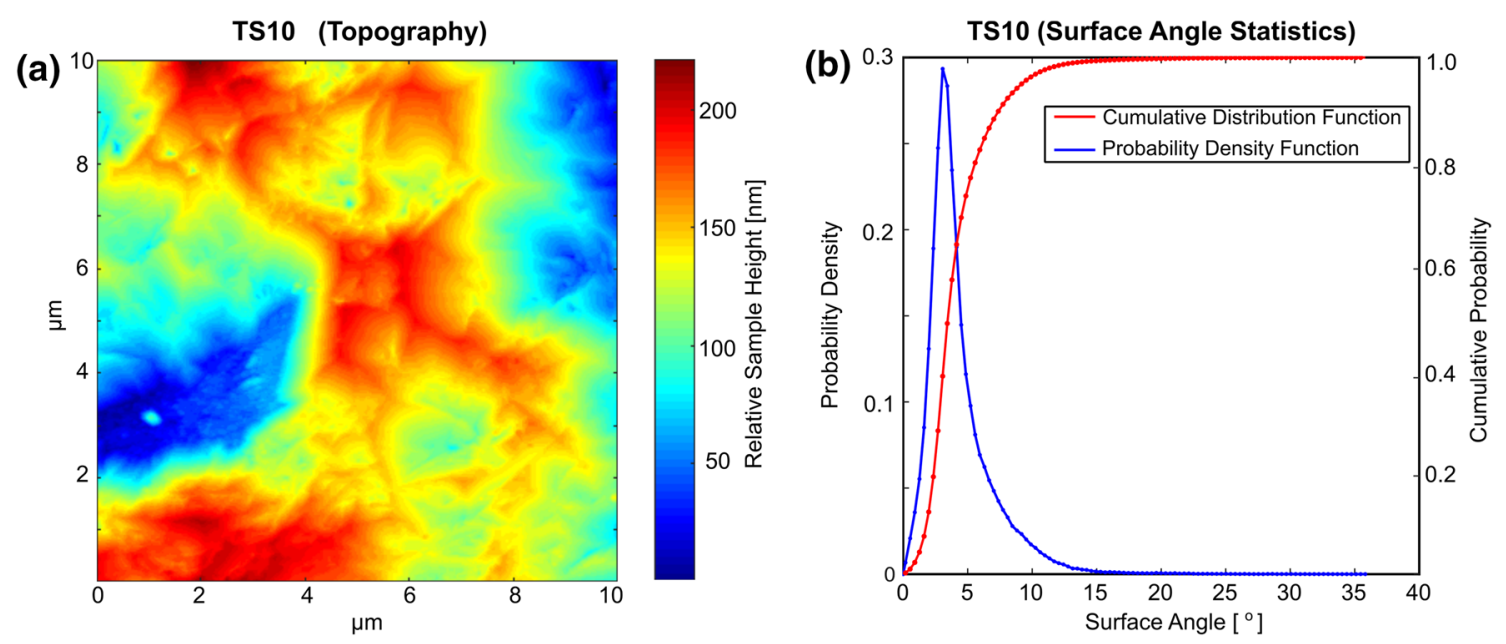

Fig. 3 a Topography map of TS10. b Probability distribution of surface angle for region in (a). The modal angle is $\approx 4^{\circ}$ with $90 \%$ of the surface with inclination of less than $10^{\circ}$ 
Fig. 4 a Schematic representation of AFM operation. b Force-distance curves during tip approach-withdraw cycle. The adhesive component is exaggerated for illustrative purposes, especially on the approach curve (a)

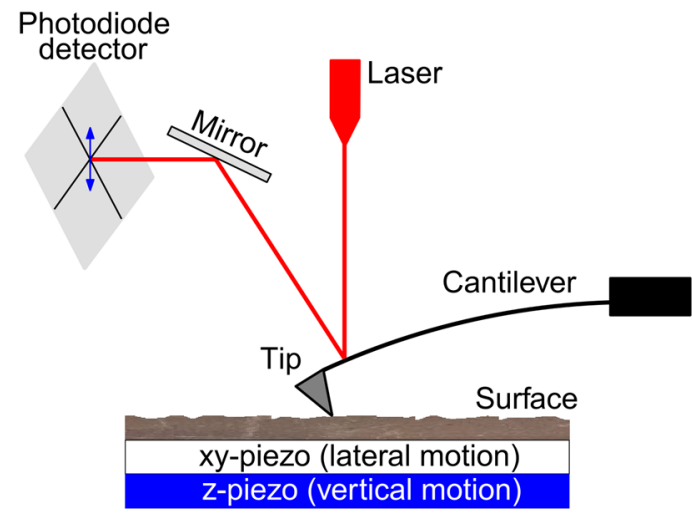

(b)

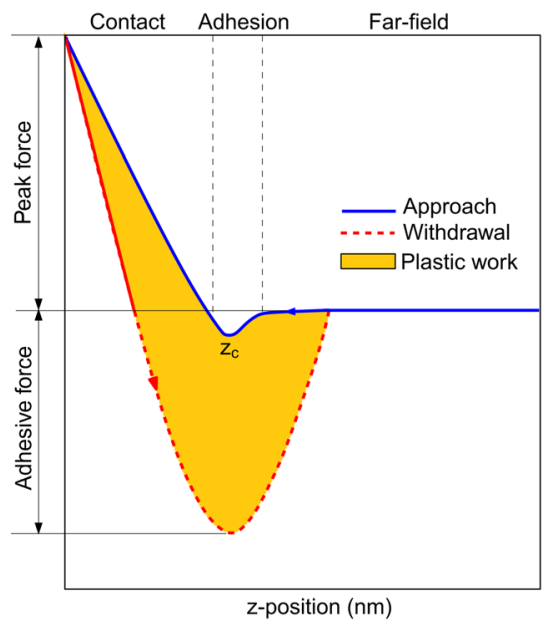

(a)

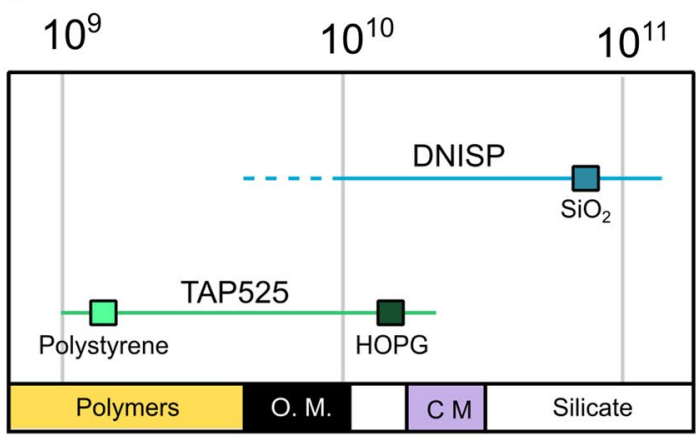

(b)

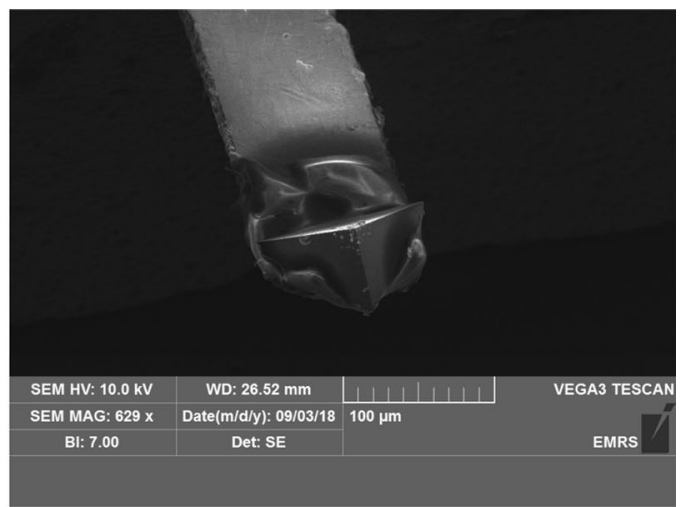

material, C.M. clay minerals. DNISP probe is a diamond tip on stainless steel cantilever; TAP525 is silicon nitride. b SEM secondary electron image of a DNISP cantilever after scanning. The presence of material removed from the sample ate tip apex should be noted

for adhesion between the tip and the sample via an additional linear term:

$F_{\text {int }}=F_{\text {hertz }}+F_{\text {adh }}$,

where $F_{\text {adh }}$ is the adhesive component of the total interaction force $F_{\text {int }}$. PF-QNM fits Eq. 3 to the retract curve (Fig $4 \mathrm{~b}$ ), (Bruker 2011a, b). QI-AFM fits Eq. 1 to the approach curve (JPK 2017), since the adhesive component is negligible compared to the retract curve, and also negligible relative to the peak interaction force/setpoint.

\subsubsection{Instrument Calibration}

The deflection sensitivity $S[\mathrm{~nm} / \mathrm{V}]$ of the cantilever, and its spring constant $k\left[\mathrm{~N} \mathrm{~m}^{-1}\right]$ need to be determined. Cantilever deflection, $D$, is initially in volts, and is converted to length through the deflection sensitivity constant. The spring constant allows applied force to be calculated by Hooke's law. 
Table 2 Cantilever and tip calibrated and nominal values for the types used in this study

\begin{tabular}{lll}
\hline Parameter & TAP525 & DNISP \\
\hline Contact tip radius $(\mathrm{nm})$ & 10 & 27 \\
Tip modulus $E_{\mathrm{t}}(\mathrm{GPa})$ & - & 1100 \\
Length $(\mu \mathrm{m})$ & 125 & 350 \\
Width $(\mu \mathrm{m})$ & 40 & 100 \\
Thickness $(\mu \mathrm{m})$ & 5.75 & 13 \\
Spring constant $k\left(\mathrm{~nm}^{-1}\right)$ & 225 & 265 \\
Deflection sensitivity $(\mathrm{nm} / \mathrm{V})$ & & \\
$\quad$ QI-AFM & 18 & 35 \\
$\quad$ PF-QNM & 37 & 83 \\
\hline
\end{tabular}

Contact radius is estimated by scanning a rough titanium standard in $\mathrm{PF}-\mathrm{QNM}$ and differs from nominal radius in the tip specifications. It is not measured directly in QI-AFM, and thus, in this case, PF-QNM values are used

To determine $S$, the tip is ramped against a sapphire standard of comparable stiffness to the tip to force negligible deformation of the sample. Representative deflection sensitivities found during calibration for both DNISP and TAP525 tips using QI-AFM and PF-QNM are given in Table 2. The QI system is less sensitive to cantilever deflection than the PF-QNM system. This results from the different photo-diode detectors are used in each system. For quartzofeldspathic and carbonate phases, the expected elastic moduli are high and the indentation of the sample surface is expected to be small. For a fixed instrumental precision, high sensitivity may lead to lower measured sample indentation and overestimation of the elastic modulus. In the case of the DNISP probes, $k$ is determined by the manufacturer.
For the TAP525, the spring constant was determined by the thermal tune method (Bruker 2011a).

For PF-QNM, the optimal scanning setpoint (maximum applied force) is determined by scanning a highly ordered pyrolytic graphite (HOPG) standard $\left(E^{*} \approx 18 \mathrm{GPa}\right)$. This is chosen as it lies within the range of clay mineral and OM stiffness (Fig. 5a). Calibration determines the force needed to give a sample deformation of at least $2 \mathrm{~nm}$ according to the manufacturer's recommendations Bruker (2011a, (2011b). Young et al. (2011) report that if $\left|E_{\text {sample }}-E_{\mathrm{HOPG}}\right| \gg 0$, the error in AFM measurement increases. Variation is expected in the $E^{*}$ of the standard, and this is accounted for by letting the value of $E^{*}$ fall within one standard deviation of the mean measured value (Trtik et al. 2012). The same approach is taken in this study. The results of calibration for both probes are given in Fig. 6. There is good agreement between expected and obtained values. QI-AFM does not require the scanning of a standard, since modulus is not calculated in real time and can only be done by processing the results in the output software. The choice of setpoint is then somewhat arbitrary. For all scans using QI-AFM in this study, a setpoint of $500 \mathrm{nN}$ was chosen.

\subsection{Nanoindentation}

To access the mechanical response at length scales above $\sim 10 \mu \mathrm{m}$, nanoindentation is employed. A relatively wellestablished technique in geomechanics compared to AFM (Bobko and Ulm 2008; Liu and Ostadhassan 2017; Liu et al. 2018; Lu et al. 2019; Akono et al. 2019; Abedi et al. 2016), only a brief overview of the technique is provided here. For composite materials, the load applied in indentation testing
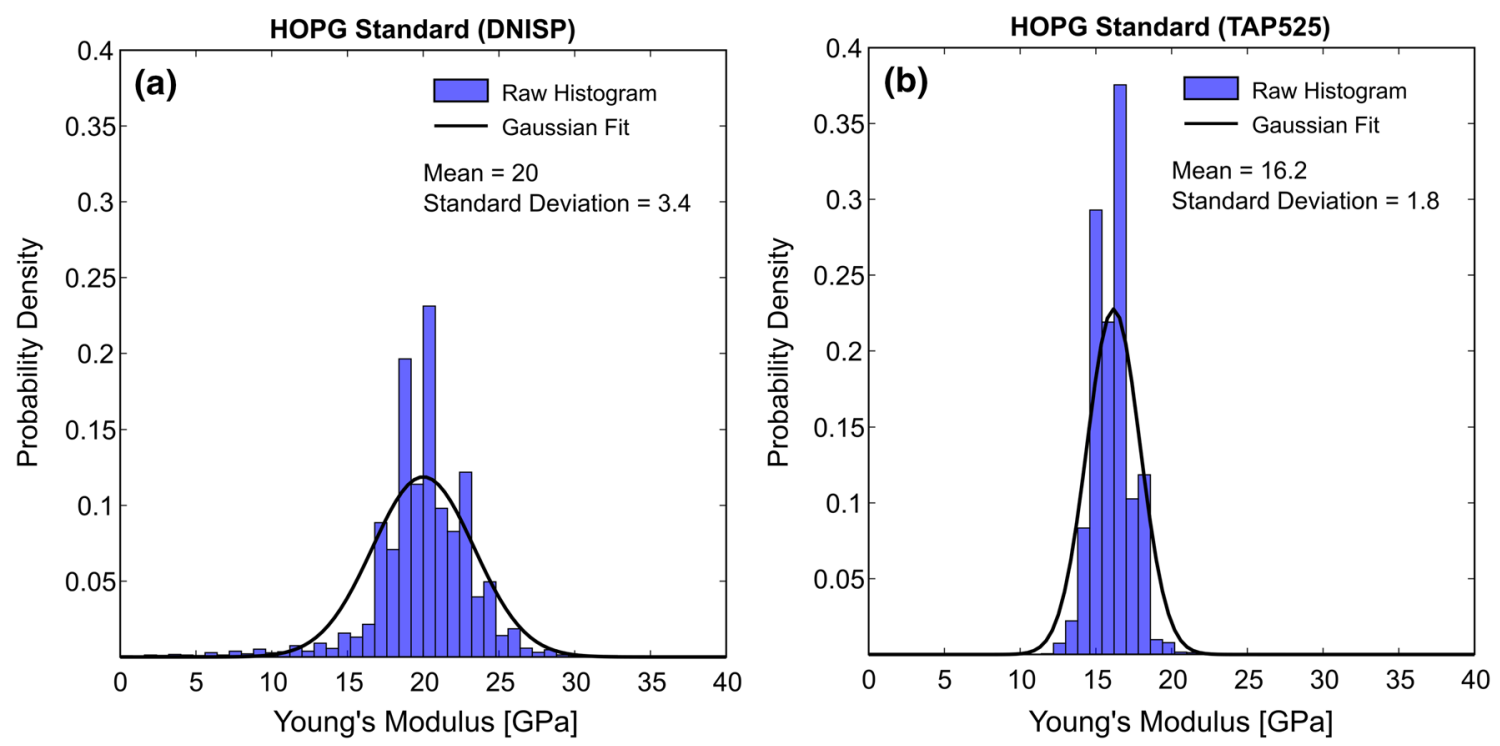

Fig. 6 Histograms derived from data acquired by PF-QNM scanning the HOPG standard using a DNISP probe and b TAP525 probe 


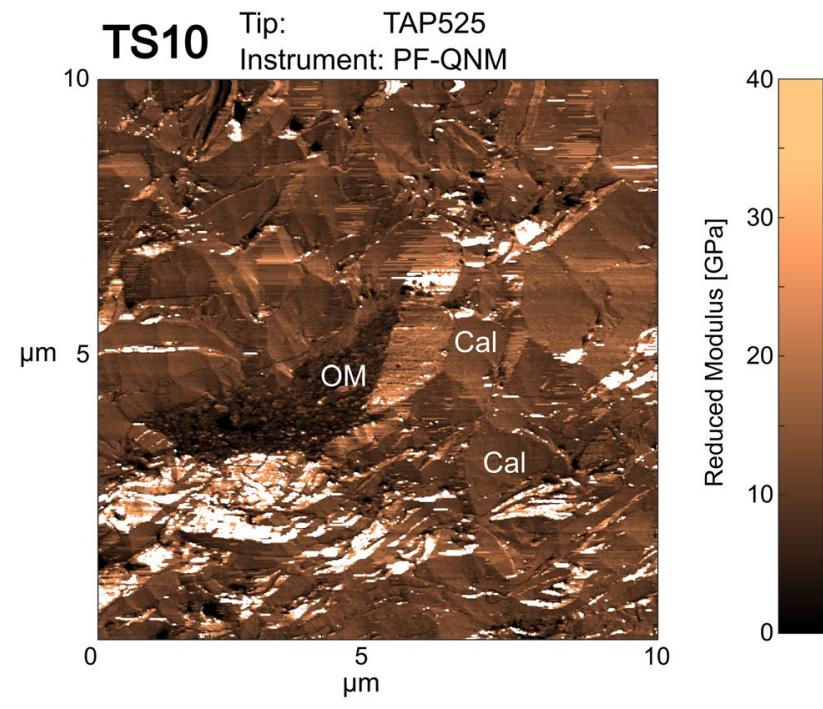

Fig. 7 Reduced modulus maps of sample TS10 as measured with a TAP525 cantilever. From the scan conducted with PF-QNM, it can be seen that in inorganic regions, a uniform background reading of $E^{*} \sim$ $25 \mathrm{GPa}$ is recorded, with some regions in white where the instrument has not resolved a stiffness value. This suggests that an upper limit on the resolution of the TAP525 is set at $25 \mathrm{GPa}$

is important to distinguish between local and bulk mechanical responses (Constantinides et al. 2006). In this study, nanoindentation is used to look at both the local and bulk response of the samples, so two load cases are considered (Fig. 7).

The local response was measured by the low-load grid indentation technique (Constantinides et al. 2006). 400 indents were applied to each sample as four randomly positioned $10 \times 10$ measurement grids (100 indents per grid). This was done to capture any contribution of local spatial variation in the sample. Indentation spacing was $5 \mu \mathrm{m}$ within each grid, with an applied load of $5 \mathrm{mN}$ in all cases. Low-load testing was carried out using a Hysitron triboindenter system (Newcastle University, UK). Bulk shale response was characterised by a single grid of $7 \times 7$ indents at $100 \mu \mathrm{m}$ separation. as per the methodology of (Goodarzi et al. 2017; Goodarzi 2018). Maximum load was $250 \mathrm{mN}$. High-load testing was carried out using a NanoTest ${ }^{\mathrm{TM}}$ Vantage system.

All nanoindentation curves were analysed using the classical approach of Oliver and Pharr (1992); Pharr et al. (1992), in which the reduced modulus, $E^{*}$, is calculated as:

$E^{*}=\left.\frac{\sqrt{\pi}}{2 \sqrt{A_{\mathrm{c}}}} \frac{\partial P}{\partial h}\right|_{h=h_{\max }}$,

where $A_{\mathrm{c}}$ is the contact area between the sample and the indenter, and $\partial P / \partial h$ is the gradient of the unloading curve at maximum indentation depth $h_{\max }$. Reduced modulus can be converted to true Young's modulus by Eq. 2. Only reduced modulus values are considered. Data from low-load tests were subject to statistical deconvolution methods to separate individual chemo-mechanical components. This was carried out using the procedure of Ulm et al. (2007).

\subsection{Mechanical Segmentation and Data Analysis}

Segmentation of AFM elastic moduli maps into organic and inorganic components was carried out through comparison to backscattered electron scanning electron microscopy (BSE), and EDX images of the same sample regions. The methodology of Camp and Wawak (2013) was applied to BSE images to produce pseudo-greyscale images for thresholding. Four greyscale classes were identified, and comparison with EDX element maps showed that these can be interpreted as organic carbon, carbonate, aluminosilicate + quartz, and 'heavy' phases (pyrite, apatite, etc.). Since thresholding is controlled by pseudo-greyscale number derived from BSE images, separation of aluminosilicate and quartz phases was difficult due to low contrast difference. These phases were manually segmented by comparing AFM maps with SEM and EDX images. AFM data were analysed using NanoScope Wizard software v.1.9 (PF-QNM) and JPKDP software v.6.1 (QI-AFM).

\section{Results and Discussion}

We now present the results of our comparison of QI-AFM and PF-QNM measurements of elastic responses, along with a comparison between the values of elastic modulus as a function of the tip used to determine them.

\subsection{Organic Matter}

For sample $\mathrm{CC} 8$, the average modal value of $E^{*}$ for $\mathrm{OM}$ based on all instrument/probe configurations is $9.8 \pm 1.1 \mathrm{GPa}$. In the case of sample TS10, the average modal value is $5.2 \pm 1.1 \mathrm{GPa}$. In both cases, the error is the standard deviation of all instrument/probe configurations for a given sample (see Table 4 for the values used in these calculations). For each sample, the resulting organic probability density functions are shown in Fig. 8; these were used to construct confidence intervals for the expected distribution at the $95 \%$ confidence interval. For both samples, all instrument-probe configurations produce distributions that fall within the $95 \%$ confidence interval, suggesting that a high level of consistency in the mechanical responses of organic material is achieved by both PFQNM and QI-AFM systems. Additionally, the DNISP tips work as well as the TAP525 tips in the low stiffness range.

Our measurements are at the lower end of the 5-30 GPa range measured by Emmanuel et al. (2016) in mature 
kerogen. The different mean moduli between samples probably reflect chemical differences in OM, supported by observations by Jakob et al. (2019) who showed that there is significant chemo-mechanical variation even within a single sample. The effects of OM chemistry on mechanical properties are still an open question ( $\mathrm{Li}$ et al. 2018b, a; Goodarzi 2018), although some preliminary work has been done by Emmanuel et al. (2016), who suggest that increasing maturity causes stiffening in organic material. Eliyahu et al. (2015) suggested that co-existing of kerogen and bitumen has distinct mechanical properties.

For sample TS10, PF-QNM produces a slightly higher modal reduced modulus for OM when compared to QIAFM. The higher deflection sensitivity of the cantilevers used on the PF-QNM system may explain this, since this lowers the resolution with which the instrument can detect cantilever bending. This results in underestimation of the true deflection, leading to the measurements being artificially stiff. The opposite is seen for CC8. For sensitivity alone to explain these differences, we should also expect the experiments run with the TAP525 to yield a lower $E^{*}$ than the DNISP probes, regardless of instrument, as a TAP525 has lower deflection sensitivity than a DNISP probe for both instruments (Table 2). For TS10, however, TAP525 tips give higher modal values than DNISP probes. These results suggest that overall the differences in sensitivities between probes and instruments do not play a significant role in the measured Young's modulus distribution, with differences being attributable to experimental error.

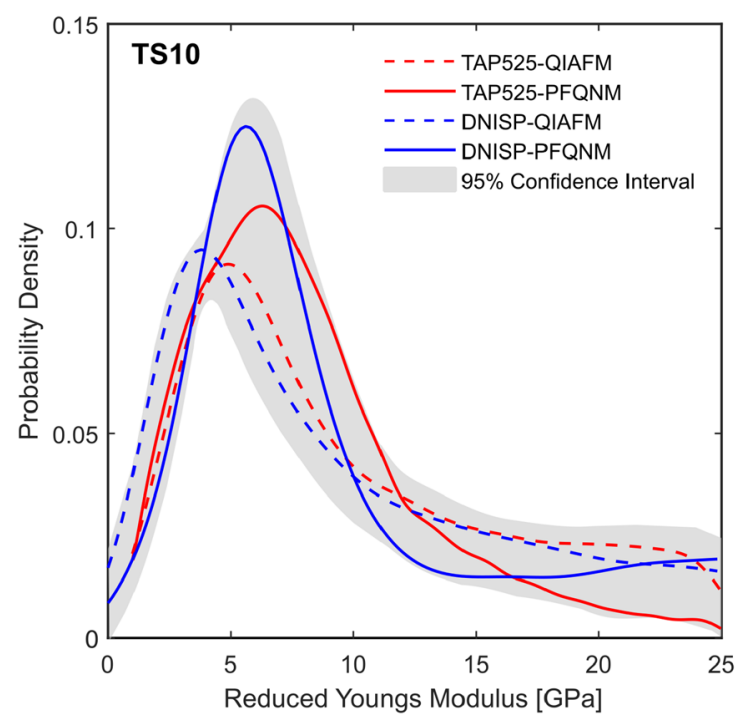

DNISP probes produce a greater difference in modal $E^{*}$ between instruments, $2.2 \mathrm{GPa}$ for CC 8 and $1.8 \mathrm{GPa}$ for TS10 compared to differences of $0.9 \mathrm{GPa}$ and $1.4 \mathrm{GPa}$ for $\mathrm{CC} 8$ and TS10, respectively using TAP525. This is attributed to the fact that in the case of OM, DNISP probes are working at their lower operational limit. Indeed, Pittenger et al. (2014) put the lower operational limit of DNISP probes at $10 \mathrm{GPa}$ (solid blue line in Fig. 5a), so we are theoretically out of cantilever capability when dealing with OM. The generally comparable results when compared to the TAP525 response for both samples suggest that the values obtained are still valid. Moreover, this suggests that the lower limit of DNISP probes can be taken down to $\sim 5 \mathrm{GPa}$.

\subsection{Inorganic Phases}

In these samples, non-clay inorganic components are generally physically larger, and more volumetrically dominant than both clay minerals and organic material (Table 1). It is thus possible to measure their mechanical response using low-load nanoindentation as well as AFM.

\subsubsection{Atomic Force Microscopy and Nanoindentation}

Once segmented, AFM data were fitted to a kernel density function to estimate probability density functions. Due to the $25 \mathrm{GPa}$ operational limit of TAP525 tips (see Fig. 7), only DNISP probes are considered for this part of the study. Reduced moduli results from AFM are shown in Fig. 9a, b, with low-load nanoindentation results in Fig. 9c, d.

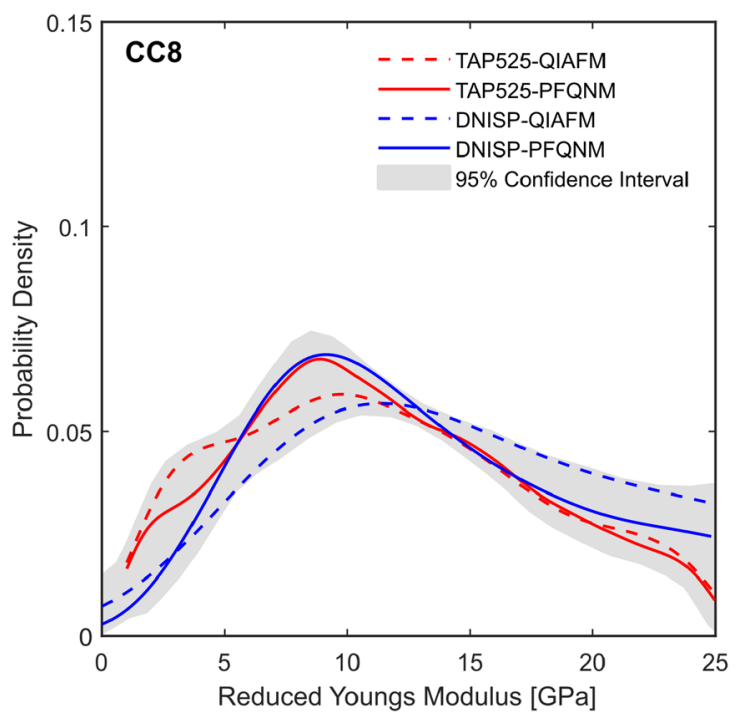

Fig. 8 Probability density functions (PDF) for the reduced Young's modulus, $E^{*}$, of organic matter in samples CC8 and TS10. The PDFs are determined using the kernel density estimator approach 
Table 3 Numerical results of deconvolution of nanoindentation results shown in Fig. 9

\begin{tabular}{|c|c|c|c|c|c|c|c|c|c|}
\hline \multirow[t]{3}{*}{ Sample } & \multicolumn{3}{|c|}{ Phase A } & \multicolumn{3}{|c|}{ Phase B } & \multicolumn{3}{|c|}{ Phase C } \\
\hline & \multicolumn{3}{|c|}{ Clay-OM-Pore } & \multicolumn{3}{|c|}{ Calcite } & \multicolumn{3}{|c|}{ Quartzofeldspathic } \\
\hline & $f_{A}$ & $E^{*}(\mathrm{GPa})$ & $\sigma_{E}(\mathrm{GPa})$ & $f_{B}$ & $E^{*}(\mathrm{GPa})$ & $\sigma_{E}(\mathrm{GPa})$ & $f_{C}$ & $E^{*}(\mathrm{GPa})$ & $\sigma_{E}(\mathrm{GPa})$ \\
\hline CC8 & 0.06 & 24.6 & 5.1 & 0.68 & 41.9 & 6.3 & 0.26 & 56.5 & 8.4 \\
\hline TS10 & - & - & - & 0.74 & 40.6 & 6.5 & 0.26 & 55.2 & 8.0 \\
\hline
\end{tabular}

$f_{i}$ component weighting, $E^{*}$ mean reduced modulus, $\sigma_{E}$ the corresponding standard deviation
The fine-scale intergrowth of clay minerals and organic matter means that segmentation of these phases is incomplete, reflected in small secondary peaks in the inorganic probability density functions at $E^{*} \approx 10 \mathrm{GPa}$. PF-QNM results for sample CC8 show a peak at $E^{*} \approx 22 \mathrm{GPa}$ that is not present in sample TS10. This is interpreted as the response of clay minerals, as EDS mapping of CC8 indicates localised packets of clay materials (Figs. 1,2) which are not present in the region studied within TS10.

A third peak is present in both samples between 40 and $50 \mathrm{GPa}$. This peak defines the dominant inorganic phase in TS10 and contributes half the total probability density in CC8. We infer that this phase is calcite and note that the modulus values between 40 and $50 \mathrm{GPa}$ are somewhat lower than those previously measured for calcite in similar fine-grained sedimentary rocks. Using PF-QNM and a DNISP probe, Eliyahu et al. (2015) reported Young's moduli of $53 \pm 6 \mathrm{GPa}$ for calcite, whilst Emmanuel et al. (2016, (2017) measured values around $55 \mathrm{GPa}$, again using a PF-QNM setup.

The modulus values corresponding to calcium carbonate are in agreement with other studies of similar rocks. Eliyahu et al. (2015) report calcite to have reduced Young's modulus of $53 \pm 6 \mathrm{GPa}$, using PF-QNM and a DNISP probe. Emmanuel et al. (2016, (2017) also note calcite in the range of 55 $\mathrm{GPa}$, again using a PF-QNM setup.

The results of the deconvolution of nanoindentation data are presented in Table 3. For CC 8 and TS10, the phase interpreted as calcite has reduced moduli of $\sim 40 \pm 6.5 \mathrm{GPa}(1 \sigma)$, very similar to the results from PF-QNM. For TS10 values of $40 \mathrm{GPa}$ are measured by both techniques, with $\mathrm{CC} 8$ yielding $50 \mathrm{GPa}$ from AFM and $42 \mathrm{GPa}$ from nanoindentation. The AFM results for $\mathrm{CC} 8$ is outside one standard deviation of the nanoindentation result of $41.9 \mathrm{GPa} \pm 6.3$; however, inspection of the histogram CC 8 shows that mean value for calcite should be closer to $45 \mathrm{GPa}$. This mismatch arises, because the deconvolution algorithm simultaneously solves for material hardness (Table 4).

Moduli of 40-50 GPa are much lower than those reported for calcite crystals obtained by acoustic methods. Chen et al. (2001) report bulk and shear moduli of $76.1 \mathrm{GPa}$ and 32.8 GPa, respectively using Brillouin spectroscopy, corresponding to a Young's modulus of 86 GPa. Mavko et al. (2009)
Table 4 Summary results of reduced Young's modulus for minerals and organic matter measured by AFM and low-load nanoindentation

\begin{tabular}{lll}
\hline Organic matter & \multicolumn{2}{l}{ Modal $E^{*}(\mathrm{GPa})$} \\
\cline { 2 - 3 } & $\mathrm{CC} 8$ & $\mathrm{TS} 10$ \\
\hline PF-QNM & & 6.3 \\
$\quad$ TAP525 & 8.9 & 5.6 \\
$\quad$ DNISP & 9.2 & \\
QI-AFM & 9.8 & 4.9 \\
$\quad$ TAP525 & 11.4 & $5.8( \pm 1.1)$ \\
$\quad$ DNISP & $9.8( \pm 1.1)$ & \\
Mean modal $E^{*}(\mathrm{GPa})$ & Mean $E^{*}(\mathrm{GPa})$ & \\
Clay & $22( \pm 2.0)$ & - \\
$\quad$ PF-QNM & $24.6( \pm 5.1)$ & - \\
$\quad$ Low-load nanoindentation & Mean $E^{*}(\mathrm{GPa})$ & \\
Calcite & $50( \pm 9.2)$ & $42( \pm 8.1)$ \\
$\quad$ PF-QNM & $41.9( \pm 6.3)$ & $40.6( \pm 6.5)$ \\
$\quad$ Low-load nanoindentation & Mean $E^{*}(\mathrm{GPa})$ & \\
Quartz and feldspar & - & $55.5( \pm 10.1)$ \\
$\quad$ PF-QNM & $56.5( \pm 8.4)$ & $55.2( \pm 8.0)$ \\
$\quad$ Low-load nanoindentation & &
\end{tabular}

Organic matter Young's modulus is calculated as the mean of the modal values measured using each instrument-tip configuration on a sample. The error is \pm standard deviation of modal values. For inorganic phases, the error on AFM is \pm the peak half-width. Low-load indentation error is taken as the standard deviation for each phase returned by the deconvolution procedure

suggest a value of $60 \mathrm{GPa}$. The difference in Young's moduli reflects the morphology of calcite. Experiments used to determine the full set of elastic constants typically use large crystals, whereas calcite in sedimentary rocks typically is of biological origin or is micritic, with the majority of calcite existing as clay like platelets rather than well-defined euhedral crystals. Measured Young's moduli for micrite areas show areas as low as 1-20 GPa (Zhang et al. 2018) up to $70 \mathrm{GPa}$ (Fournier et al. 2011), with many values in the range 30-50 GPa (Vialle and Lebedev 2015). De Paula et al. (2010) present nanoindentation data for oolitic limestone that has a bimodal distribution with a major peak at $56 \mathrm{GPa}$.

Bobko and Ulm (2008) carried out an extensive nanoindentation study of clay-rich shales, from which they determined the mechanical properties of 'solid clay' by 


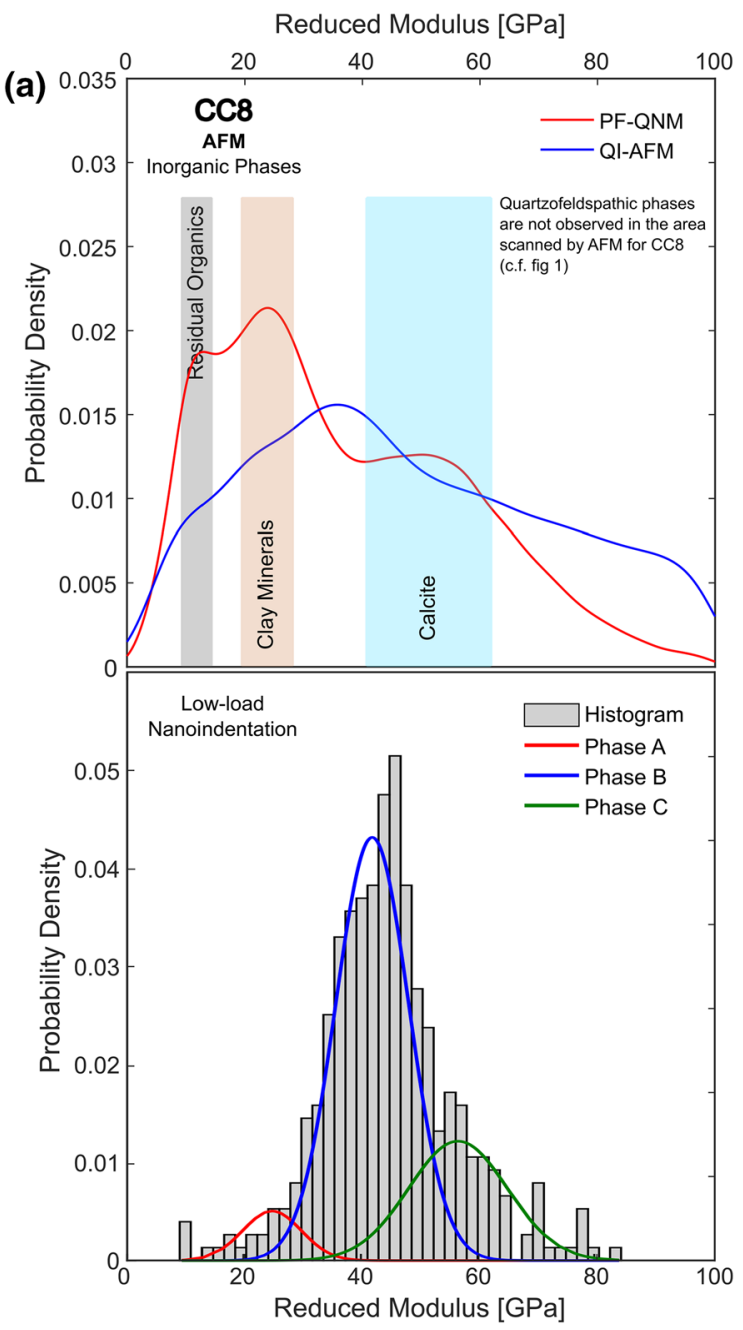

Fig. 9 Probability density functions for the reduced modulus of inorganic phases from a CC8 and b TS10 measured by both AFM systems (upper panel) and histograms of raw low-load nanoindentation results (lower panel) overlain by probability density functions of the

extrapolation to a packing density of unity, i.e., zero porosity. For the bedding perpendicular direction, they report a Young's modulus of $25 \mathrm{GPa}$, similar to values (a) obtained through inversion of ultrasonic pulse velocity tests in a micro-mechanics framework (Ortega et al. 2007) and (b) this study $\sim 22$ GPa by PF-QNM.

Our segmented AFM results for combined plagioclase and quartz give a single peak with a mean $E^{*}$ of $55 \mathrm{GPa}$ (Fig. 9, in good agreement with the results of deconvolution from low-load nanoindentation tests. As for calcite, these values are lower than those reported in the literature on larger crystals. Mavko et al. (2009)'s compilation of Young's moduli of quartz gives a range of 77-96 GPa, and Zhu et al. (2007) carried out nanoindentation quartz crystals in granite yielding $E^{*}$ of $101 \mathrm{GPa}$. The elastic properties of feldspars are strongly dependent on their chemistry. Brown et al.

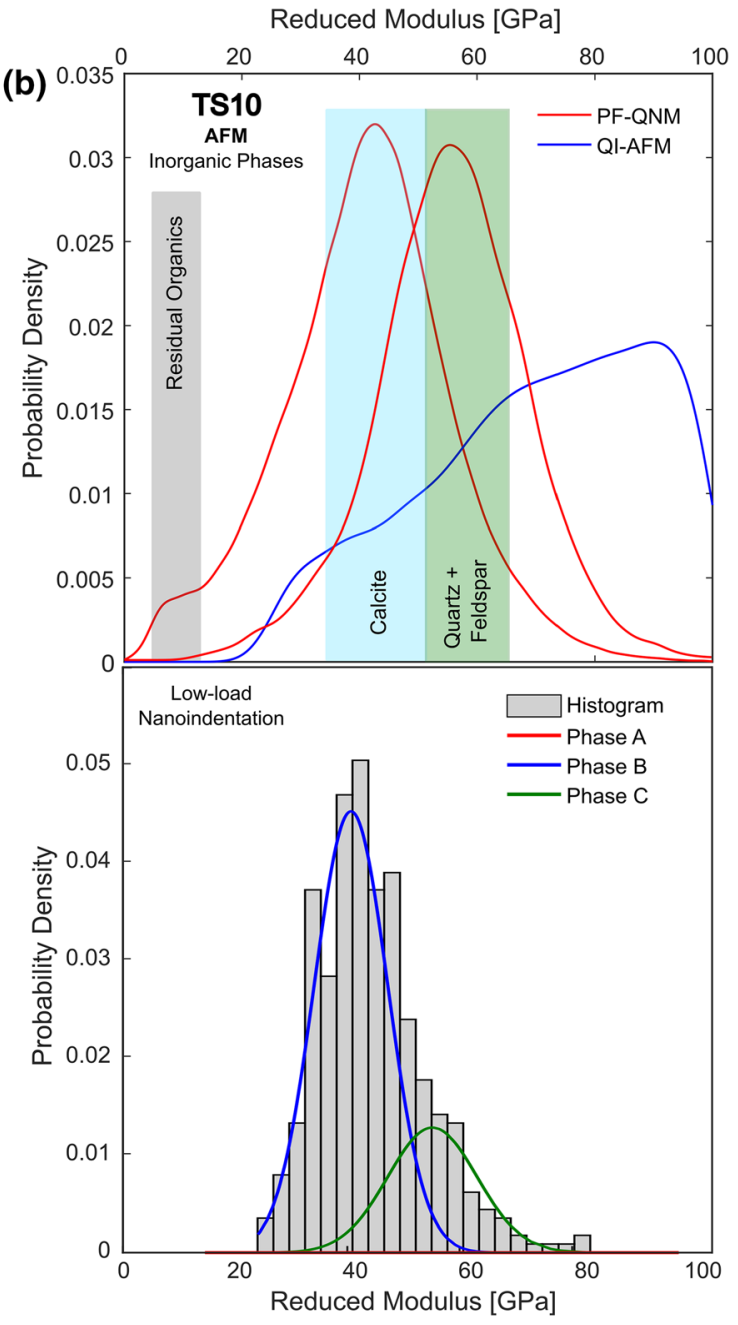

reduced modulus of the mechanically active phases based on the results of deconvolution. The numerical results of deconvolution are provided in Table 3. 400 indents were used in the analysis of each sample

(2016) give a range of Young's modulus which varies in the range of $87 \mathrm{GPa}$ for albite $\mathrm{An}_{0}$ to $103 \mathrm{GPa}$ for anorthite $\mathrm{An}_{100}$, with labradorite $\left(\mathrm{An}_{50-70}\right)$ having a Young's modulus of $97 \mathrm{GPa}$. Using nanoindentation, Zhu et al. (2007) measured $E^{*} \approx 62 \mathrm{GPa}$ for albite in granite.

One explanation for the lower Young's moduli for quartz and feldspar in our study would be the occurrence of microporosity (Ulm et al. 2007; Goodarzi et al. 2016), which can amount to a few volume percent in feldspars (Worden et al. 1990) as a result of dissolution reactions and also diagenetic transformation to clay minerals (Jin et al. 2011). The small tip size of the DNISP probe used in this study $(\sim 30$ $\mathrm{nm}$ ) results in deformations of $\sim 2 \mathrm{~nm}$, so that the mechanical properties measured by AFM may be expected to vary depending on the amount of microporosity sampled at each point of contact. On the other hand, the larger tip size of the 
(a)

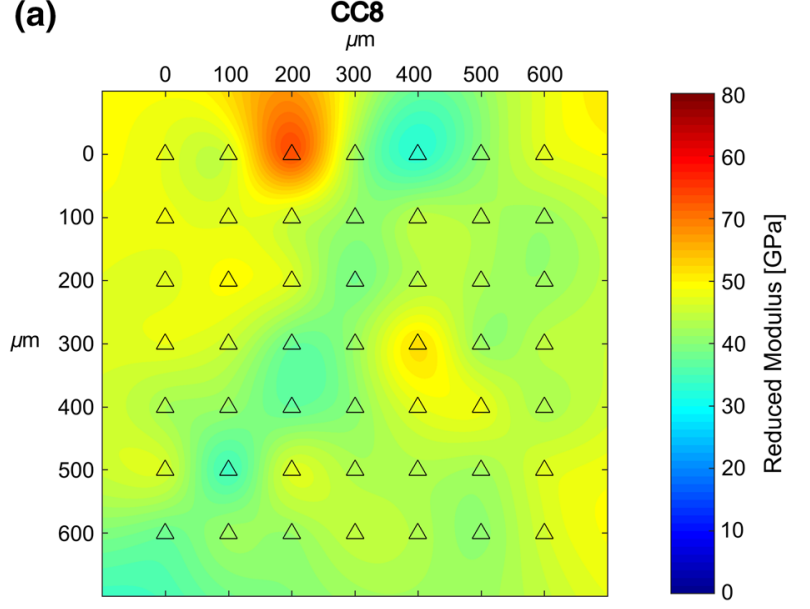

(c)
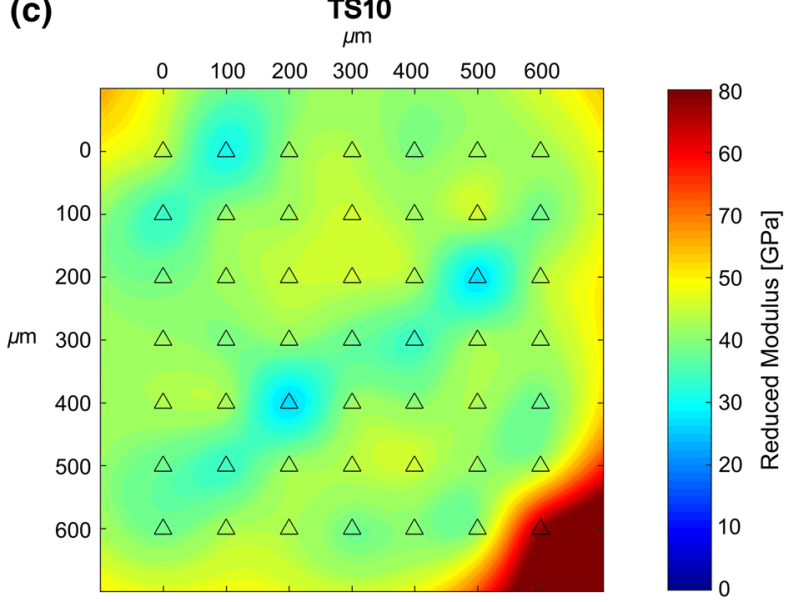

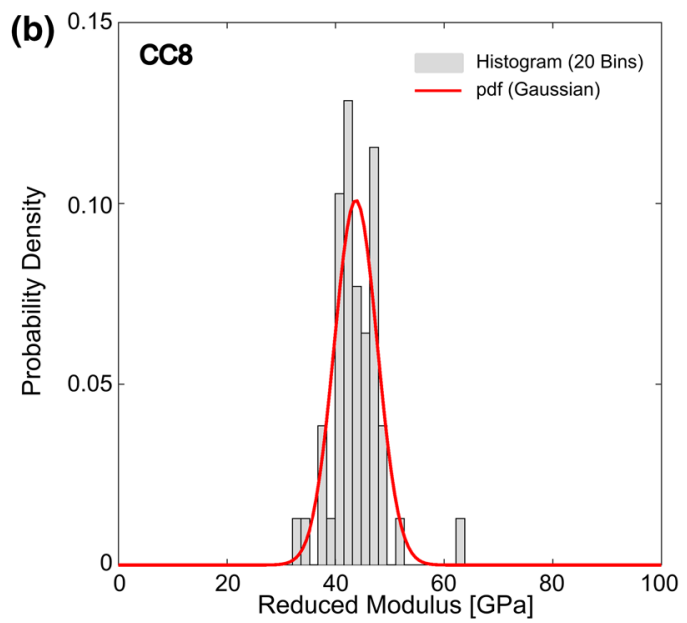

(d)

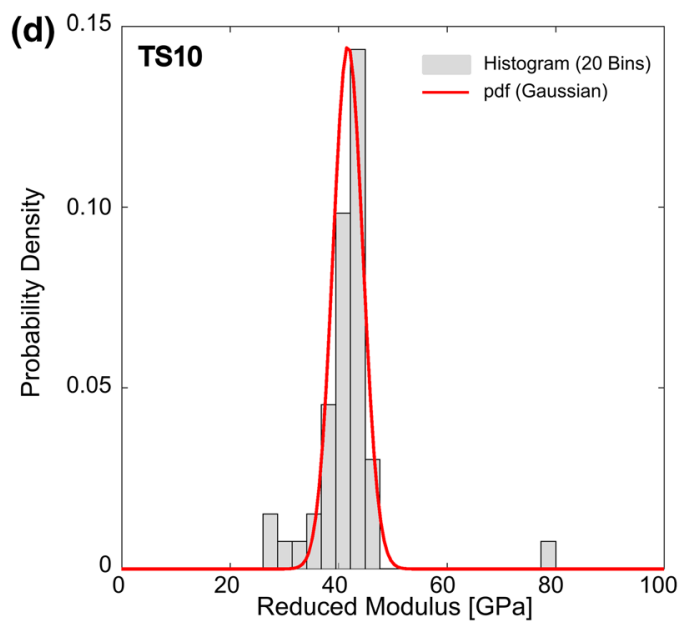

Fig. 10 a Reduced modulus map of sample CC8. b Histogram of raw data, overlain by best-fit normal distribution. c Reduced modulus map of sample TS10. d Histogram and best-fit normal distribution

Berkovich indenter will sample a more representative volume of feldspar microporosity. Since our results from AFM and nanoindentation are similar, we infer that both methods approximate the bulk mechanical response of the mineral grains, and that it is the differing micro-morphology of both feldspars and quartz in fine-grained sedimentary rocks, compared to igneous rocks and more ideal crystals, which is most likely to explain the lower Young's modulus.

\subsubsection{High-Load Nanoindentation}

The results of high-load nanoindentation testing are presented in Fig. 10. Figure 10a, c shows the map of reduced modulus over an area $600 \times 600$ microns for CC8 and TS10, respectively, compared to an area of $95 \times 95$ microns for low-load tests, and $10 \times 10$ microns for AFM. The corresponding modulus histograms are shown in Fig. 10b, d.
Table 5 Mean $\left(E_{\text {Bulk }}^{*}\right)$ and standard deviation $(\sigma)$ of bulk Young's modulus derived from $n$ high-load nanoindentation tests for CC8 and TS10

\begin{tabular}{|c|c|c|c|c|c|c|c|c|}
\hline \multirow[t]{2}{*}{ Sample } & \multirow[t]{2}{*}{$n$} & \multicolumn{3}{|c|}{ Perpendicular $\left(x_{1}\right)$} & \multicolumn{3}{|l|}{ Parallel $\left(x_{3}\right)$} & \multirow[t]{2}{*}{$E_{1} / E_{3}$} \\
\hline & & $E_{\text {Bulk }}^{*}(\mathrm{GPa})$ & $\sigma(\mathrm{GPa})$ & $\pm E_{95}^{*}$ & $E_{\text {Bulk }}^{*}(\mathrm{GPa})$ & $\sigma(\mathrm{GPa})$ & $\pm E_{95}^{*}$ & \\
\hline $\mathrm{CC} 8$ & 49 & 43.5 & 4.0 & 1.12 & 34.8 & 3.4 & 0.95 & 1.25 \\
\hline TS10 & 49 & 41.8 & 2.8 & 0.78 & 34.1 & 5.6 & 1.57 & 1.23 \\
\hline
\end{tabular}

The $95 \%$ confidence interval $( \pm 1.96 \sigma / \sqrt{n})$ on the mean $\left( \pm E_{95}^{*}\right)$ is also given. Note that composite Young's moduli are reported for sections cut parallel in addition to those perpendicular to the bedding surface used in the rest of this study 
Figure 10b, d, shows a single well-defined modulus peak for both samples, in contrast to the bimodal and trimodal distributions from low-load tests in Fig. 9c, d. Summary statistics for the best-fit Gaussian distributions to the highload test data are given in Table 5. The high-load bulk responses of both samples are similar, around $42 \mathrm{GPa}$, and also in agreement with the results of the low-load indentation and AFM tests. Moduli around $42 \mathrm{GPa}$ are consistent with the bulk response being controlled by the major mineral phase present in these samples, calcite (Table 1), with similar amounts of both stiffer (quartz and feldspar) and softer (clay and organic material) in both samples.

\subsection{Implications for Upscalling and Anisotropy}

It is useful to consider the general implications of our new results for future micro-mechanical modelling of the elasticity of organic-rich calcareous shales. We do this by computing the Voigt and Reuss bounds for a simplified four-component shale comprising of organic matter, clay, calcite, and quartzofeldspathic phases (Fig. 11). Similar simplified conceptual models are have been used previously, however, our use of a four-component system reflects the availability of a robust micro-mechanical data set. This is less conservative in its predictions than the very general two-component models used by previous authors where shales are divided into generally soft and stiff phases (Mavko et al. 2009; Bayuk et al. 2008; Sone and Zoback 2013a, b; Herrmann et al. 2018). Hill (1963) used an energy balance argument to show that the Voigt and Reuss bounds must be considered as upper and lower bounds, respectively, on the Young's modulus of a composite material. Therefore, we must observe the highload nanoindentation composite Young's modulus falling within these bounds.

The Voigt bound is the arithmetic mean of the individual Young's moduli of minerals in a shale sample, and the Reuss bound is a harmonic mean based on the same
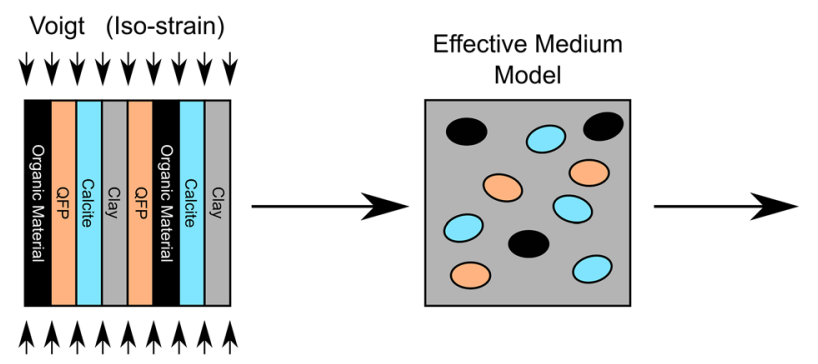

Reuss (Iso-stress)
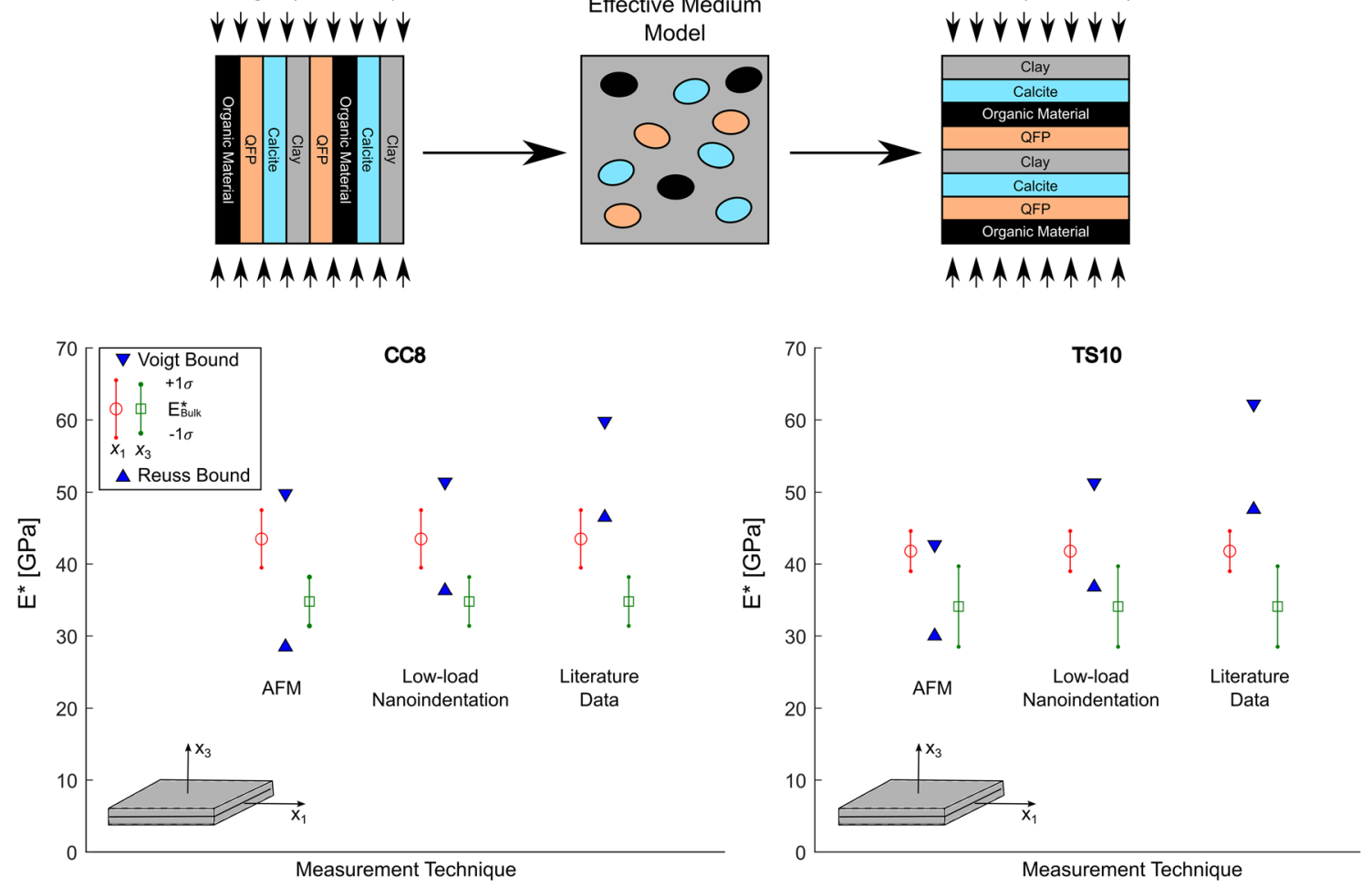

Fig. 11 Young's modulus from high-load indentation $\left(E_{\mathrm{Bulk}}\right)$ and the corresponding Voigt, and Reuss bounds on the homogenised Young's modulus based on the measured component responses using AFM and low-load nanoindentation and literature data. AFM bounds are calculated using the XRD mineral volumes using a simplified mineralogy of Quartz + Feldspar, Calcite, Clay $(=\mathrm{Chl}+\mathrm{I}-\mathrm{S} / \mathrm{ML})$, and TOC. Moduli used in the calculations are listed in Table 4, with the Voigt and Reuss bounds calculated using the mean \pm the peak halfwidth, respectively. Low-load indentation bounds are calculated

using the fractions in Table 3. The corresponding reduced moduli are the mean \pm one standard deviation for the Voigt and Reuss bounds, respectively. Values based on literature data table values use the fractions from low-load indentation tests as it is felt that allows the bounds based on literature data to reflect component interactions in the shale composite, thus providing better constraints on the value of the bounds. $E_{\mathrm{Cly}+\mathrm{TOC}+\mathrm{Pore}}=25 \mathrm{GPa}$ (Bobko and Ulm 2008), $E_{\mathrm{QFP}}=60 \mathrm{GPa}$ and $E_{\mathrm{QFP}}=83 \mathrm{GPa}$ (Mavko et al. 2009) 
input parameters. They are calculated from information about components in the composite using Eq. 5, where $f_{i}$ represents the $i$ th fraction of an $N$ component mixture with a corresponding Young's modulus $E_{i}$. These bounds are calculated as follows:

$E_{\text {Voigt }}=\sum_{i=1}^{N} f_{i} E_{i} \quad$ and $\quad E_{\text {Reuss }}=\left[\sum_{i=1}^{N} \frac{f_{i}}{E_{i}}\right]^{-1}$.

The robustness of the measured data can be demonstrated by computing Voigt and Reuss bounds on the composite material using AFM and low-load nanoindentation data. Results of these calculations are presented in Fig. 11. It can be seen that Voigt and Reuss bounds obtained from mineral moduli using either AFM or low-load nanoindentation provide better constraints on the high-load bulk response. It should be noted that there is a difference between locally measured AFM and low-load data. This is likely due to the fact that volume fractions used for AFM data in Eq. 5 are derived from XRD (Table 1), whereas the bounds computed from low-load indentation data use the fractions extracted from deconvolution. This suggests that it may be better to represent shale in terms of its mechanically active phases rather than its mineralogical ones, allowing consideration of both microstructural (e.g., inter-grain interactions, cementation, etc.) and mechanical variation (e.g., grain orientation and intra-grain chemo-mechanical variation).

In contrast, it can be observed from Fig. 11 that when $E_{\mathrm{Bulk}}$ is calculated using mineral moduli from the literature, the results for the bounds are higher than the bulk response measured using high-load nanoindentation. Even when the experimental error in the high-load indentation data is taken into account, the bulk responses do not reach the Reuss bound using published moduli for highly crystalline quartz, calcite, and feldspar. The error bars on the composite Young's modulus in Fig. 11 represent one standard deviation. If we consider the $95 \%$ confidence interval on the mean as less conservative measure of error, then it can be seen that previously assumed Young's modulus values for quartz and calcite do not seem to provide bounds on the composite that adequately reflect the homogenised Young's modulus.

The use of previously assumed moduli for mineral phases for estimation of the composite elastic responses is still prevalent in the homogenisation literature (Giraud et al. 2007; Ortega et al. 2007; Guéry et al. 2010; Goodarzi et al. 2017; Zhang et al. 2020) despite the potential for significant overestimation of the true value as demonstrated by our results. This emphasises the need to use micro-mechanically appropriate Young's modulus values for all component phases when estimating the components of the composite stiffness matrix $C_{i j}$ from mineralogical data, not just the clay matrix as in previous studies (Ulm and Abousleiman 2006; Bobko and
Ulm 2008). The assumption that macroscopically derived elastic moduli are appropriate may lead to bounding values on the composite that are energetically inconsistent based on the results of Hill (1963). Indeed, where calibration of a mean-field homogenisation model is carried out with respect to the clay matrix, the interpretation of the obtained constants (e.g., in terms clay mineralogy) may be undermined by the assumed Young's moduli of the inclusion phases. This is due to the calibrated clay phase which will be acting to correct for other inaccuracies in the model.

The anisotropy of shale is of importance in many field applications relating to wellbore stability and seismic interpretation (Ortega et al. 2007; Sayers et al. 2015). Therefore, it is advantageous to include it in micro-mechanical studies to understand the origins of macro-scale anisotropy. The scaling of the Young's modulus of shale building blocks over several orders of magnitude conducted in this work allows for advanced micro-mechanical modelling work, where anisotropy is explicitly considered in determining the elastic constants. Figure 11 shows that when XRD mineral fractions are used in conjunction with the values reported in Table 4, the composite Young's modulus in both the $x_{1}$ and $x_{3}$ material directions (bedding parallel and normal respectively) falls within the calculated bounds. Provided that a suitable estimated on the transversely anisotropic clay matrix is used, this implies that the values for calcite and quartz-feldspar obtained in this study are valid for use in typical two-level conceptual homogenisation models (Ulm et al. 2005).

The mineral components of shale, with the exception of $\mathrm{OM}$ and pyrite are intrinsically anisotropic. Deposition of mineral grains of quartz, calcite, and feldspar on the bedding surface can be considered a random process. Additionally, the low energy of deposition associated with shale can lead to no preferred crystal orientation. This has the effect of averaging out the effects of intrinsic crystal anisotropy as it is manifested in the low-load indention results. Since the grids cover a large region of the sample relative to grain size, this results in the indentations encountering numerous locally varied crystal orientations. This results in the deconvolution procedure producing a singular peak representative of the equivalent isotropic material.

In Fig. 11, if the bounds are calculated using the fractions from deconvolution in Eq. 5, then only the composite Young's modulus in the $x_{1}$ direction falls within them. This being the same direction in which low-load indentation was carried out. Deconvolution fractions are partially a product of inter-particle interactions representing mechanically active phases. Calcite is normally considered an inclusion, and considered mechanically isotropic from a modelling perspective. However, given the volumetric dominance of calcite, it is interesting to note that the bulk Young's modulus in the $x_{3}$ direction does not fall inside the mechanical bounds for either sample when deconvolution fractions are 
used. This observation poses an interesting question as to whether or not calcite needs to be considered in an anisotropic manner given the comparatively low volume of clay relative to calcite in the studied samples. From a practical perspective, the majority of homogenisation studies continue to use XRD data to inform component volumes. Therefore, there is still practical merit in using the values in Table 4 for isotropic inclusions. Future work should focus on the mechanical character of calcite in calcareous shales. We have already noted the good agreement of the indentation modulus for clay measured by AFM in this study, and that reported by Ulm and Abousleiman (2006); Bobko and Ulm (2008); Ortega (2010). This suggest in part that the elastic constants of Ortega et al. (2007) for a transversely isotropic clay matrix would be suitable starting points for more advanced micro-mechanical modelling of the shales considered in this study in conjunctions with the results in Table 4 .

\subsection{Measured Modulus and Length Scales}

The total area covered by our low-load indentation grids is $9025 \mu \mathrm{m}^{2}$, compared to $100 \mu \mathrm{m}^{2}$ for AFM scans. AFM measures variation in Young's modulus over a single or a few mineral grains, whereas deconvolution of nanoindentation data samples the average stiffness of a phase from a much larger number of individual grains. Despite the difference in the length scale of observation, the spread in the distribution of moduli for both calcite and quartz-feldspar about their respective means is similar for both AFM and low-load indentation (see Fig. 9). The agreement between AFM and low-load nanoindentation is surprisingly good given that the Young's modulus on inorganic phases is $20-30 \mathrm{GPa}$ larger than the HOPG standard used to calibrate the AFM. In future, the use of AFM to determine mechanical properties of complex natural composite materials may be advantageous since whilst individual indentation measurements can take up to $5 \mathrm{~min}$ to obtain, and AFM scan of $\sim 2.6 \times 10^{5}$ measurements can be acquired in around $30 \mathrm{~min}$.

\section{Conclusions}

This study has presented the first direct in situ comparison between the mechanical response of rock forming minerals over length scales from $\sim 10 \mathrm{~nm}$ to $\sim 100 \mu \mathrm{m}$ by combining AFM, low-load and high-load nanoindentation approaches. We present the first multi-instrument approach to assess the mechanical response of organic matter, and demonstrate a highly consistent response which can be obtained, yielding Young's modulus in the range $E^{*}=5-10 \mathrm{GPa}$. This implies that AFM is a viable tool to answer more detailed questions about organic matter mechanics with implications for cap rock leakage and petroleum expulsion.
AFM with a DNISP probe and low-load nanoindentation give similar results for the Young's moduli of clay $(22 \pm 2.0 \mathrm{GPa})$, calcite $(40-50 \pm 8.5 \mathrm{GPa})$, quartz, and feldspar ( $55 \pm 10.1)$. For non-clay, inorganic phases, the mechanical responses in terms of Young's modulus are significantly lower than previous measurements obtained on macro-scale highly crystalline phases, but similar to other in situ studies of individual minerals in sedimentary rocks.

High-load nanoindentation generates a unimodal responses in the range 40-50 GPa for both samples studied here, and are consistent with calcite being the major mechanically active phase, from low-load nanoindentation and AFM results. We have calculated, Voigt, Reuss, and Voigt-Reuss-Hill bounds on the bulk response using lowload nanoindentation, AFM, and literature values for individual mineral phases. Low-load nanoindentation and AFM data provide the best estimates for constraints on the composite response at length scales of $\sim 100-600 \mu \mathrm{m}$ measured from high-load indentation data. Conversely, moduli measured on highly crystalline macro-scale mineral phases do not provide effective bounds on the composite response. This questions the validity of using such macro-scale measurements in homogenisation schemes, and suggests that more emphasis should be placed on the use of nano- and micromechanical measurements when using effective medium theories and homogenisation schemes to predict the bulk mechanical response. Homogenising to length scales of $\sim 100 \mu \mathrm{m}$ may be considered the 'undamaged' homogeneous response, thus better prediction of properties at this scale, which may allow for a more realistic inclusion of damage and microcracks into homogenisation schemes and a better prediction of Young's modulus at triaxial scale.

Since low-load nanoindentation data intrinsically couple mineral mechanical properties with how they interact with their microstructural context, it may be better to conceptualise shale in terms of its mechanically active phases, rather than purely in terms of its mineralogical phases thus allowing us to include mechanical responses arising from microstructural factors into homogenisation schemes without additional mathematical complexity.

Acknowledgements S. Graham is funded under an EPSRC CASE studentship (EP5095281). M. Rouainia is supported by NERC (Grant NE/ R018057/1). A.C. Aplin is supported by NERC (Grant NE/R017840/1). T. Fender is supported by the NERC Doctoral Training Partnership (GrantNE/M00578X/1).

\section{Compliance with Ethical Standards}

Conflict of interest The authors declare that they have no conflict of interest.

Open Access This article is licensed under a Creative Commons Attribution 4.0 International License, which permits use, sharing, adaptation, distribution and reproduction in any medium or format, as long 
as you give appropriate credit to the original author(s) and the source, provide a link to the Creative Commons licence, and indicate if changes were made. The images or other third party material in this article are included in the article's Creative Commons licence, unless indicated otherwise in a credit line to the material. If material is not included in the article's Creative Commons licence and your intended use is not permitted by statutory regulation or exceeds the permitted use, you will need to obtain permission directly from the copyright holder. To view a copy of this licence, visit http://creativecommons.org/licenses/by/4.0/.

\section{References}

Abedi S, Slim M, Ulm FJ (2016) Nanomechanics of organic-rich shales: the role of thermal maturity and organic matter content on texture. Acta Geotech 11(4):775-787

Akono A, Kabir P, Shi Z, Fuchs S, Tsotsis TT, Jessen K, Werth CJ (2019) Modeling $\mathrm{CO}_{2}$-induced alterations in Mt. Simon sandstone via nanomechanics. Rock Mech Rock Eng 52(5):1353-1375

Amirmajdi OM, Ashyer-Soltani R, Clode MP, Mannan SH, Wang Y, Cabruja E, Pellegrini G (2009) Cross-section preparation for solder joints and mems device using argon ion beam milling. IEEE Trans Electron Packag Manuf 32(4):265-271

Armitage PJ, Faulkner DR, Worden RH, Aplin AC, Butcher A, Iliffe J (2011) Experimental measurement of, and controls on, permeability and permeability anisotropy of caprocks from the $\mathrm{CO}_{2}$ storage project at the Krechba field, Algeria. J Geophys Res 116(B12)

Baihly JD, Altman RM, Malpani R, Luo F et al (2010) Shale gas production decline trend comparison over time and basins. Soc Petrol Eng. https://doi.org/10.2118/135555-MS

Bayuk IO, Gay JK, Hooper JM, Chesnokov EM (2008) Upper and lower stiffness bounds for porous anisotropic rocks. Geophys J Int 175(3):1309-1320

Bobko C, Ulm FJ (2008) The nano-mechanical morphology of shale. Mech Mater 40(4-5):318-337

Borodich FM, Bull SJ, Epshtein SA (2015) Nanoindentation in studying mechanical properties of heterogeneous materials. J Min Sci 51(3):470-476

Brown JM, Angel RJ, Ross NL (2016) Elasticity of plagioclase feldspars. J Geophys Res 121(2):663-675

Bruker (2011a) Multimode8 with scanasyst instruction manual

Bruker (2011b) Nanoscope software 8.10 user guide

Burnham NA, Colton RJ (1989) Measuring the nanomechanical properties and surface forces of materials using an atomic force microscope. J Vac Sci Technol A 7(4):2906-2913

Camp WK, Wawak B (2013) Enhancing sem grayscale images through pseudocolor conversion: examples from Eagle Ford, Haynesville, and Marcellus shales. In: Unconventional resources technology conference, society of exploration geophysicists. American Association of Petroleum Geologists, pp 2300-2307

Chen CC, Lin CC, Liu LG, Sinogeikin SV, Bass JD (2001) Elasticity of single-crystal calcite and rhodochrosite by Brillouin spectroscopy. Am Mineral 86(11-12):1525-1529

Constantinides G, Chandran KSR, Ulm FJ, van Vliet KJ (2006) Grid indentation analysis of composite microstructure and mechanics: principles and validation. Mater Sci Eng 430(1-2):189-202

Daigle H, Hayman NW, Kelly ED, Milliken KL, Jiang H (2017) Fracture capture of organic pores in shales. Geophys Res Lett 44(5):2167-2176

Davies RJ, Foulger GR, Bindley A, Styles P (2013) Induced seismicity and hydraulic fracturing for the recovery of hydrocarbons. Mar Petrol Geol 45:171-185
De Paula O, Pervukhina M, Gurevich B, Lebedev M, Martyniuk M, Delle Pane C (2010) Estimation of carbonate elastic properties using nanoindentation and digital images. In: 72nd EAGE conference and exhibition incorporating SPE EUROPEC 2010

Derjaguin BV, Muller VM, Toporov YP (1975) Effect of contact deformations on the adhesion of particles. J Colloid Interface Sci 53(2):314-326

Eliyahu M, Emmanuel S, Day-Stirrat RJ, Macaulay CI (2015) Mechanical properties of organic matter in shales mapped at the nanometer scale. Mar Petrol Geol 59:294-304

Emmanuel S, Eliyahu M, Day-Stirrat RJ, Hofmann R, Macaulay CI (2016) Impact of thermal maturation on nano-scale elastic properties of organic matter in shales. Mar Petrol Geol 70:175-184

Emmanuel S, Eliyahu M, Day-Stirrat RJ, Hofmann R, Macaulay CI (2017) Softening of organic matter in shales at reservoir temperatures. Petrol Geosci 23(2):262-269

Fender TD, Rouainia M, Van Der Land C, Jones DM, Mastalerz M, Hennisen JAI, Graham SP, Wagner T (2020) Geomechanical properties of coal macerals; measurements applicable to modelling swelling of coal seams during $\mathrm{CO}_{2}$ sequestration. Int $\mathrm{J}$ Coal Geol 103528

Fournier F, Leonide P, Biscarrat K, Gallois A, Borgomano J, Foubert A (2011) Elastic properties of microporous cemented grainstones. Geophysics 76(6):E211-E226

Fournier F, Léonide P, Kleipool L, Toullec R, Reijmer J, Borgomano J, Klootwijk T, Van Der Molen J (2014) Pore space evolution and elastic properties of platform carbonates (Urgonian limestone, Barremian-Aptian, SE France). Sediment Geol 308:1-17

Giraud A, Huynh QV, Hoxha D, Kondo D (2007) Application of results on Eshelby tensor to the determination of effective poroelastic properties of anisotropic rocks-like composites. Int J Solids Struct 44(11-12):3756-3772

Goodarzi M (2018) Geomechanical characterisation of organic-rich shale properties using small scale experiments and homogenisation methods. PhD thesis, Newcastle University

Goodarzi M, Rouainia M, Aplin AC (2016) Numerical evaluation of mean-field homogenisation methods for predicting shale elastic response. Comput Geosci 20(5):1109-1122

Goodarzi M, Rouainia M, Aplin AC, Cubillas P, de Block M (2017) Predicting the elastic response of organic-rich shale using nanoscale measurements and homogenisation methods. Geophys Prospect 65(6):1597-1614

Goulty NR (2003) Reservoir stress path during depletion of Norwegian chalk oilfields. Petrol Geosci 9(3):233-241

Guéry AAC, Cormery F, Shao JF, Kondo D (2010) A comparative micromechanical analysis of the effective properties of a geomaterial: effect of mineralogical compositions. Comput Geotech 37(5):585-593

Herrmann J, Rybacki E, Sone H, Dresen G (2018) Deformation experiments on Bowland and Posidonia shalepart I: strength and Youngs modulus at ambient and in situ $p_{c}$-t conditions. Rock Mech Rock Eng 51(12):3645-3666

Hill R (1963) Elastic properties of reinforced solids: some theoretical principles. J Mech Phys Sol 11(5):357-372

Ingram GM, Urai JL (1999) Top-seal leakage through faults and fractures: the role of mudrock properties. In: Aplin AC, Fleet AJ, Macquaker JHS (eds) Muds and mudstones: physical and fluid-flow properties, vol 158. Geological Society of London Special Publications, pp 125-135

Jakob DS, Wang L, Wang H, Xu XG (2019) Spectro-mechanical characterizations of kerogen heterogeneity and mechanical properties of source rocks at $6 \mathrm{~nm}$ spatial resolution. Anal Chem

Jin L, Rother G, Cole DR, Mildner DFR, Duffy CJ, Brantley SL (2011) Characterization of deep weathering and 
nanoporosity development in Shalea neutron study. Am Mineral 96(4):498-512

JPK (2017) Data processing software manual

Kumar V, Sondergeld CH, Rai CS et al (2012) Nano to macro mechanical characterization of shale. Soc Petrol Eng. https://doi. org/10.2118/159804-MS

Li C, Ostadhassan M, Gentzis T, Kong L, Carvajal-Ortiz H, Bubach B (2018a) Nanomechanical characterization of organic matter in the Bakken formation by microscopy-based method. Mar Petrol Geol 96:128-138

Li C, Ostadhassan M, Guo S, Gentzis T, Kong L (2018b) Application of PeakForce tapping mode of atomic force microscope to characterize nanomechanical properties of organic matter of the Bakken shale. Fuel 233:894-910

Liu K, Ostadhassan M (2017) Microstructural and geomechanical analysis of Bakken shale at nanoscale. J Petrol Sci Eng 153:133-144

Liu K, Ostadhassan M, Bubach B (2018) Application of nanoindentation to characterize creep behavior of oil shales. J Petrol Sci Eng 167:729-736

Loucks RG, Reed RM, Ruppel SC, Jarvie DM (2009) Morphology, genesis, and distribution of nanometer-scale pores in siliceous mudstones of the mississippian Barnett shale. J Sediment Res 79(12):848-861

Loucks RG, Reed RM, Ruppel SC, Hammes U (2012) Spectrum of pore types and networks in mudrocks and a descriptive classification for matrix-related mudrock pores. AAPG Bull 96(6):1071-1098

Lu Y, Li Y, Wu Y, Luo S, Jin Y, Zhang G (2019) Characterization of shale softening by large volume-based nanoindentation. Rock Mech Rock Eng 1-17

Mavko G, Mukerji T, Dvorkin J (2009) The rock physics handbook Tools for seismic analysis of porous media, 2nd edn. Cambridge University Press, Cambridge

Militzer B, Wenk HR, Stackhouse S, Stixrude L (2011) First-principles calculation of the elastic moduli of sheet silicates and their application to shale anisotropy. Am Mineral 96(1):125-137

Monfared S, Ulm FJ (2016) A molecular informed poroelastic model for organic-rich, naturally occurring porous geocomposites. J Mech Phys Sol 88:186-203

Mullen J (2010) Petrophysical characterization of the eagle ford shale in South Texas (CSUG/SPE 138145)

Nygård R, Gutierrez M, Gautam R, Høeg K (2004) Compaction behavior of argillaceous sediments as function of diagenesis. Mar Petrol Geol 21(3):349-362

Nygård R, Gutierrez M, Bratli RK, Høeg K (2006) Brittle-ductile transition, shear failure and leakage in shales and mudrocks. Mar Petrol Geol 23(2):201-212

Obradors-Prats J, Rouainia M, Aplin AC, Crook AJL (2017) Assessing the implications of tectonic compaction on pore pressure using a coupled geomechanical approach. Mar Petrol Geol 79:31-43

Obradors-Prats J, Rouainia M, Aplin AC, Crook AJL (2019) A diagenesis model for geomechanical simulations: formulation and implications for pore pressure and development of geological structures. J Geophys Res 124(5):4452-4472

Oliver WC, Pharr GM (1992) An improved technique for determining hardness and elastic modulus using load and displacement sensing indentation experiments. J Mater Res 7(6):1564-1583

Ortega JA (2010) Microporomechanical modeling of shale. $\mathrm{PhD}$ thesis, Massachusetts Institute of Technology

Ortega JA, Ulm FJ, Abousleiman Y (2007) The effect of the nanogranular nature of shale on their poroelastic behavior. Acta Geotech 2(3): 155-182

Pharr GM, Oliver WC, Brotzen FR (1992) On the generality of the relationship among contact stiffness, contact area, and elastic modulus during indentation. J Mater Res 7(3):613-617
Pittenger B, Erina N, Su C (2011) Quantitative mechanical property mapping at the nanoscale with PeakForce QNM. Application note 128

Pittenger B, Erina N, Su C (2014) Mechanical property mapping at the nanoscale using peakforce qnm scanning probe technique. In: Nanomechanical analysis of high performance materials. Springer, pp 31-51

Rickman R, Mullen MJ, Petre JE, Grieser WV, Kundert D (2008) A practical use of shale petrophysics for stimulation design optimization: all shale plays are not clones of the Barnett shale. SPE

Rybacki E, Meier T, Dresen G (2016) What controls the mechanical properties of shale rocks?-part II: brittleness. J Petrol Sci Eng 144:39-58

Rybacki E, Herrmann J, Wirth R, Dresen G (2017) Creep of posidonia shale at elevated pressure and temperature. Rock Mech Rock Eng 50(12):3121-3140

Sayers C, den Boer L, Dasgupta S, Goodway B (2015) Anisotropy estimate for the Horn River Basin from sonic logs in vertical and deviated wells. Lead Edge 34(3):296-306

Smolyakov G, Formosa-Dague C, Séverac C, Duval RE, Dague E (2016) High speed indentation measures by FV, QI and QNM introduce a new understanding of bionanomechanical experiments. Micron 85:8-14

Sneddon IN (1965) The relation between load and penetration in the axisymmetric Boussinesq problem for a punch of arbitrary profile. Int J Eng Sci 3(1):47-57

Sone H, Zoback MD (2013a) Mechanical properties of shale-gas reservoir rocks part 1: static and dynamic elastic properties and anisotropy. Geophysics 78(5):D381-D392

Sone H, Zoback MD (2013b) Mechanical properties of shale-gas reservoir rocks part 2: ductile creep, brittle strength, and their relation to the elastic modulus. Geophysics 78(5):D393-D402

Thyberg B, Jahren J (2011) Quartz cementation in mudstones: sheetlike quartz cement from clay mineral reactions during burial. Petrol Geosci 17(1):53-63

Tomasetti E, Legras R, Nysten B (1998) Quantitative approach towards the measurement of polypropylene/(ethylene-propylene) copolymer blends surface elastic properties by AFM. Nanotechnology 9(4):305-315

Trtik P, Kaufmann J, Volz U (2012) On the use of peak-force tapping atomic force microscopy for quantification of the local elastic modulus in hardened cement paste. Cement Concr Res 42(1):215-221

Ulm FJ, Abousleiman Y (2006) The nanogranular nature of shale. Acta Geotech 1(2):77-88

Ulm FJ, Delafargue A, Constantinides G (2005) Experimental microporomechanics. In: Applied micromechanics of porous materials. Springer, pp 207-288

Ulm FJ, Vandamme M, Bobko C, Ortega JA, Tai K, Ortiz C (2007) Statistical indentation techniques for hydrated nanocomposites: concrete, bone, and shale. J Am Ceram Soc 90(9):2677-2692

Vialle S, Lebedev M (2015) Heterogeneities in the elastic properties of microporous carbonate rocks at the microscale from nanoindentation tests. In: SEG technical program expanded abstracts 2015. Society of Exploration Geophysicists, pp 3279-3284

Vranjes S, Misch D, Schöberl T, Kiener D, Gross D, Sachsenhofer RF (2018) Nanoindentation study of macerals in coals from the Ukrainian Donets basin. Adv Geosci 45:73-83

Worden RH, Walker FDL, Parsons I, Brown WL (1990) Development of microporosity, diffusion channels and deuteric coarsening in perthitic alkali feldspars. Contrib Mineral Petrol 104(5):507-515

Young TJ, Monclus MA, Burnett TL, Broughton WR, Ogin SL, Smith PA (2011) The use of the PeakForce quantitative nanomechanical mapping AFM-based method for high-resolution Young's modulus measurement of polymers. Meas Sci Technol 22(12):125703 
Zargari S, Prasad M, Mba KC, Mattson ED (2013) Organic maturity, elastic properties, and textural characteristics of self resourcing reservoirs. Geophysics 78(4):D223-D235

Zargari S, Canter KL, Prasad M (2015) Porosity evolution in oil-prone source rocks. Fuel 153:110-117

Zeszotarski JC, Chromik RR, Vinci RP, Messmer MC, Michels R, Larsen JW (2004) Imaging and mechanical property measurements of kerogen via nanoindentation. Geochim Cosmochim Acta 68(20):4113-4119

Zhang Y, Lebedev M, Al-Yaseri A, Yu H, Nwidee LN, Sarmadivaleh M, Barifcani A, Iglauer S (2018) Morphological evaluation of heterogeneous oolitic limestone under pressure and fluid flow using X-ray microtomography. J Appl Geophys 150:172-181
Zhang Y, Xie L, Zhao P, He B (2020) Study of the quantitative effect of the depositional layering tendency of inclusions on the elastic anisotropy of shale based on two-step homogenization. Geophys J Int 220(1):174-189

Zhu W, Hughes JJ, Bicanic N, Pearce CJ (2007) Nanoindentation mapping of mechanical properties of cement paste and natural rocks. Mater Charact 58(11-12):1189-1198

Publisher's Note Springer Nature remains neutral with regard to jurisdictional claims in published maps and institutional affiliations. 